JÉSSICA RABELO MINA ZAMBRANA

Intensidade de pixel e sua correlação com o índice de qualidade óssea de mandíbulas atróficas

São Paulo

2016 

Intensidade de pixel e sua correlação com o índice de qualidade óssea de mandíbulas atróficas

\section{Versão Original}

Dissertação apresentada à Faculdade de Odontologia da Universidade de São Paulo, pelo Programa de Pós-Graduação em Odontologia (Diagnóstico Bucal) para obter o título de Mestre em Ciências

Orientador: Prof. Dr. Claudio Costa 
Autorizo a reprodução e divulgação total ou parcial deste trabalho, por qualquer meio convencional ou eletrônico, para fins de estudo e pesquisa, desde que citada a fonte.

Catalogação-na-Publicação

Serviço de Documentação Odontológica

Faculdade de Odontologia da Universidade de São Paulo

Zambrana, Jéssica Rabelo Mina.

Intensidade de pixel e sua correlação com o índice de qualidade óssea de mandíbulas atróficas / Jéssica Rabelo Mina Zambrana ; orientador Claudio Costa. - São Paulo, 2016.

$68 \mathrm{p}$ : fig., tab. graf.; $30 \mathrm{~cm}$.

Dissertação (Mestrado) -- Programa de Pós-Graduação em Odontologia. Área de Concentração: Diagnóstico Bucal. -- Faculdade de Odontologia da Universidade de São Paulo.

Versão original

1. Tomografia Computadorizada de Feixe Cônico. 2. Intensificação de imagem radiográfica. 3. Fios ortodônticos I. Costa, Claudio. II. Título. 
Zambrana JRMZ. Intensidade de pixel e sua correlação com o índice de qualidade óssea de mandíbulas atróficas. Dissertação apresentada à Faculdade de Odontologia da Universidade de São Paulo para obtenção do título de Mestre em Ciência

Aprovado em: / /2016

\section{Banca Examinadora}

$\operatorname{Prof}(a) . \operatorname{Dr}(a)$.

Instituição: Julgamento:

$\operatorname{Prof}(a) . \operatorname{Dr}(a)$.

Instituição: Julgamento:

$\operatorname{Prof}(a) . \operatorname{Dr}(a)$.

Instituição: Julgamento: 

Agradeço a Deus por permitir essa conquista e por estar sempre guiando meus passos.

Dedico minhas vitórias e conquistas à pessoa que me ensinou tudo o que sou hoje e tenho eterna gratidão pelos valores ensinados, dedico minha evolução a ele, Meu herói, Meu Pai...

Aos meus irmãos Nataly e André por estarem sempre apoiando minhas decisões e por me ajudarem nessa etapa, sou muito grata pela união que temos, acredito que esse cuidado mútuo é o verdadeiro significado da família, muito obrigada pela paciência, ajuda em todos os detalhes e por estarem sempre comigo; amo vocês. 



\section{AGRADECIMENTOS}

Ao meu orientador Prof. Dr. Claudio Costa, muito obrigada pela experiência, confiança, por sempre estar disposto a me ajudar em tudo; e por ter me ensinado tantas coisas durante esses anos de estágio e mestrado, não tenho dúvidas que nossa equipe é unida pelo seu entusiasmo pela pesquisa e a humildade de sempre querer aprender e ensinar, tenho muito prestígio e orgulho de ser sua orientada.

Ao Prof. Dr. Jorge de Sá Barbosa pela colaboração na elaboração da metodologia utilizada no estudo.

Aos Professores do Programa de Diagnóstico Bucal, muito obrigada pelos ensinamentos, experiências e pelo incentivo: Profa. Dra. Marlene Fenyo Soeiro de Matos Pereira, Profa. Dra. Emiko Saito Arita, Profa. Dra. Silvia Vanessa Lourenço Prof. Dr. Jefferson Xavier de Oliveira, Prof. Dr. Israel Chilvarquer, Prof. Dr. Cláudio Fróes de Freitas, Prof. Dr. César Ângelo Lascala, e Prof. Dr. Marcelo de Gusmão Paraíso Cavalcanti;

À Secretária da Radiologia: Maria Aparecida Pinto (Cidinha), muito obrigada pela ajuda em tudo! Foi essencial para que tudo desse certo, sempre me ajudando em tudo que estava em seu alcance.

Meus amigos do programa, muito obrigada pela amizade, companheirismo e ajuda em tudo que precisei: Isabela, Marina, Denise, Juliana, Reinaldo, Arthur, Cinthia e Cibele; e meu muito obrigada aos amigos Dani, Rô e Edu, cada um me ajudou de uma forma nessa etapa, Dani pelas experiências, ajuda em cada detalhe e pela amizade; Rô pelo companheirismo, incentivo e ajuda nos trabalhos feitos; Edu pela enorme ajuda nos resultados desse trabalho, sempre disposto a me ajudar em tudo; agradeço muito por serem meus amigos de verdade. 

"A vida é uma peça de teatro que não permite ensaios. Por isso cante, chore dance, ria $e$ viva intensamente, antes que a cortina se feche e a peça termine sem aplausos".

Charlie Chaplin 



\section{RESUMO}

Zambrana JRM. Intensidade de pixel e sua correlação com o índice de qualidade óssea de mandíbulas atróficas [dissertação]. São Paulo: Universidade de São Paulo, Faculdade de Odontologia; 2016. Versão Original.

O sucesso do tratamento de implantes dentários depende da quantidade e qualidade óssea da área de interesse e o uso da Tomografia Computadorizada por Feixe Cônico (TCFC) pode ser correlacionado para a sua estimativa. $O$ objetivo deste estudo foi avaliar e comparar os níveis de escala de cinza dos voxels de imagens obtidas por TCFC de mandíbulas atróficas com o auxílio de programa para diagnóstico e planejamento de implantes e correlacionar a Intensidade Pixel (IP) com a classificação subjetiva do Índice de Qualidade Óssea (IQO). Foram avaliadas imagens tomográficas de 10 mandíbulas atróficas obtidas do banco de dados do LAPI-FOUSP (Laboratório para Análise e Processamento de Imagens) que receberam 8 marcações em regiões normalmente utilizadas para colocação de implantes (4 em região anterior e 4 em região posterior), sobre estas foram posicionados fios ortodônticos para padronização dos cortes tomográficos e simular posições ideais de implantes. Cortes transaxiais das áreas demarcadas foram obtidas para visualização e análise de 4 regiões corticais e 3 regiões trabeculares do tecido ósseo de cada corte, para a seleção de área foi utilizada a ferramenta Região de Interesse (ROI) de cada programa. As imagens foram analisadas por 3 programas de planejamento Romexis (Planmeca,Finlandia), XoranCAT® (Xoran Technologies, EUA) e OsiriX® (Free Software Foundation, 32 bits, EUA). Os dados foram submetidos a análise estatística de Correlação de Spearman em um nível de significância de $5 \%(p<0,05)$, análise de correlação intraclasse intra-observador e inter-observador pelo teste Kappa ponderado e o teste qui-quadrado. Os resultados apresentaram que os programas Romexis e OsiriX apresentaram melhor acuidade para a avaliação subjetiva de qualidade óssea, em contrapartida o programa Xoran apresentou inconsistência de dados. Concluiu-se que há correlação entre Intensidade de Pixel e Qualidade óssea de acordo com os resultados encontrados para os programas OsiriX e Romexis

Palavras-chave: Tomografia Computadorizada de Feixe Cônico. Intensidade de Pixel. Qualidade Óssea. 



\begin{abstract}
Zambrana JRM. Pixel intensity and its correlation with bone quality index of atrophic mandibles [dissertation]. São Paulo: Universidade de São Paulo, Faculdade de Odontologia; 2016. Versão Original.
\end{abstract}

The success of dental implants treatment depends on the bone quantity and quality of the area of interest and the use of Cone Beam Computed Tomography (CBCT) can be correlated to an estimative. The aim of this study was to evaluate and compare the grey scale levels of voxels obtained by CBCT of atrophic mandibles with the aid of software for diagnosis and planning implants and correlates the Pixel Intensity (PI) with the subjective classification of Bone Quality Index (BQI). Tomographic images of 10 atrofic mandibles obtained from the data base of LAPIFOUSP (Laboratory of analysis and imaging processing) were evaluated, received 8 marks in areas normally used for implant placement (4 in anterior and 4 in posterior region) on these orthodontic wires were positioned for standardization of tomographic images and simulate optimal implant positions. Transaxial slices of the demarcated areas were made for visualization and analysis of four regions of interest for cancellous bone and three regions of interest for cortical bone and for selection of each area a tool called Region of Interest (ROI) was used by each software. The images were analised by three diferent planning software, Romexis (Planmeca, Finland), XoranCAT® (Xoran Technologies, EUA) e OsiriX® (Free Software Foundation, 32 bits, EUA). Data were subjected to statistical analysis of Spearman correlation, intraclass intra-observer and inter-observer analysis correlation and weighted Kappa concordance coefficient with $5 \%$ significance level and chi-squared test; The results presented that Romexis and OsiriX software showed better accuracy for subjective assessment of bone quality, on the other hand Xoran software showed data inconsistency. This study concluded that a correlation was found between Pixel Intensity $(\mathrm{PI})$ and Bone Quality (BQ) due to the results of OsiriX and Romexis software.

Keywords: Cone Beam Computed Tomography. Pixel intensity. Bone Quality 



\section{LISTA DE ILUSTRAÇÕES}

Figura 2.1 - Classificação de Densidade Óssea segundo Misch (1989) .29

Figura 2.2 - Classificação de Qualidade Óssea segundo Lekholm e Zarb (1985)...33

Figura 4.1 - Corte Axial com as demarcações das regiões 8 regiões. 40

Figura 4.2 - Tela do programa Xoran após a geração de imagem de reconstrução panorâmica e corte transaxial

Figura 4.3 - Tela do programa Romexis após a geração de imagem de reconstrução panorâmica e corte transaxial. 41

Figura 4.4 - Tela do programa Osirix com a individualização do corte transaxial.... 42

Figura 4.5 - Cortes Transaxiais, com as demarcações de ROI de $1,57 \mathrm{~mm}^{2}$ em corticais de crista óssea e osso basal

Figura 4.6 - $\mathrm{ROI}$ de $1,57 \mathrm{~mm}^{2}$ 43

Figura 4.7 - Índice de Qualidade Óssea (IQO) e suas quatro classificações segundo Tozog lu Ü e Çakur B, (2014).

Figura 4.8 - Interpretação estatístico do Kappa Ponderado 46

Figura 4.9 - Interpretação estatístico de correlação de Spearman 46

Gráfico 5.1- Frequência de IQO para região anterior 



\section{LISTA DE TABELAS}

Tabela 5.1 - Frequência de IQO para região anterior em porcentagem

Tabela 5.2- Frequência de IQO para região posterior em porcentagem

Tabela 5.3- Valores de freqüência entre observados e esperados para o teste quiquadrado(Xoran-Romexis)

Tabela 5.4- Valores de freqüência entre observados e esperados para o teste quiquadrado(Osirix-Xoran).

Tabela 5.5- Valores de freqüência entre observados e esperados para o teste quiquadrado(OsiriX-Romexis).

Tabela 5.6- Correlação de Spearman entre IP e IQO 52

Tabela 5.7- Teste Estatístico Kappa Ponderado intra-observador para a variável IQO. 53

Tabela 5.8- Teste Estatístico Kappa Ponderado inter-observador para a variável IQO .54 

Bits $\quad$ Dígito Binário (Binary Digit)

BMD Densidade Mineral Óssea (Bone Mineral Density)

CEP Comitê de Ética em Pesquisa

DICOM Digital Imaging and Communication in Medicine

Et al., Abreviatura de et al.,li

FOV Campo de Visão (Field of view)

IQO Índice de Qualidade Óssea

IP Intensidade de Pixel

kV Quilovoltagem

$\mathrm{mA} \quad$ Miliamperagem

Micro- CT Microtomografia Computadorizada

$\mathrm{mm} \quad$ milímetros

Pixel Elemento de Imagem (Picture Element)

ROI Região de Interesse (Region of interest)

TC Tomografia Computadorizada

TCFC Tomografia Computadorizada de Feixe Cônico

TCMS Tomografia Computadorizada Multi-Slice

UH Unidade de Hounsfield

Voxel Elemento de Volume (Volume element) 



\section{LISTA DE SÍMBOLOS}

$\begin{array}{ll}\% & \text { Porcentagem } \\ \mathrm{X} & \text { Versus } \\ \mathrm{S} & \text { segundos } \\ < & \text { menor que } \\ \pm & \text { Mais ou menos (desvio padrão) }\end{array}$





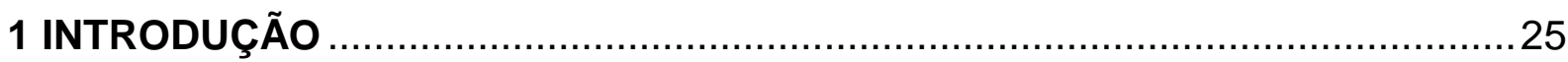

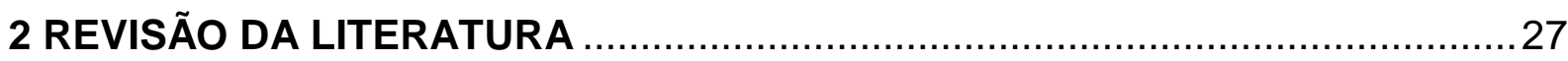

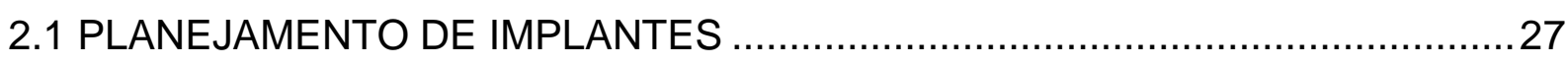

2.2 TOMOGRAFIA COMPUTADORIZADA E DENSIDADE ÓSSEA …..................28

2.3 TOMOGRAFIA COMPUTADORIZADA DE FEIXE CÔNICO …..........................29

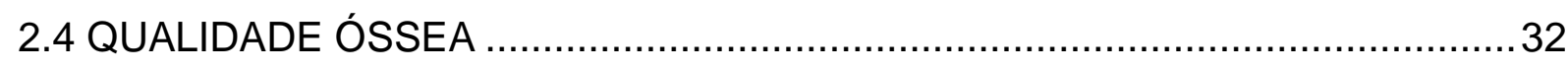

3 PROPOSIÇÃO

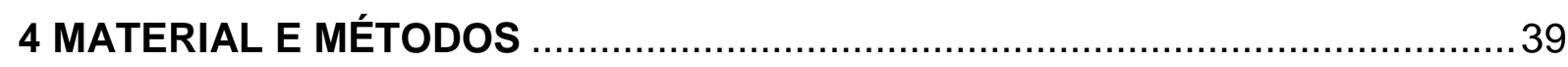

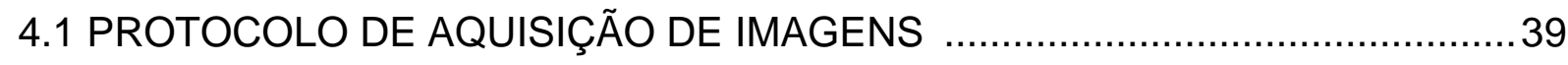

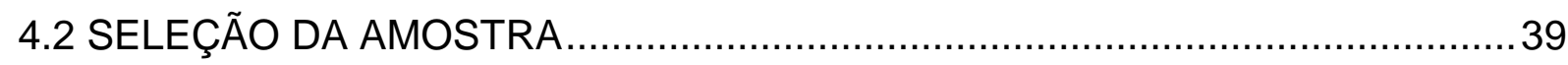

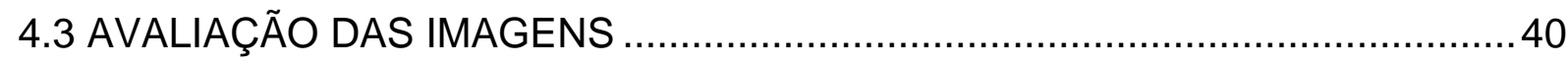

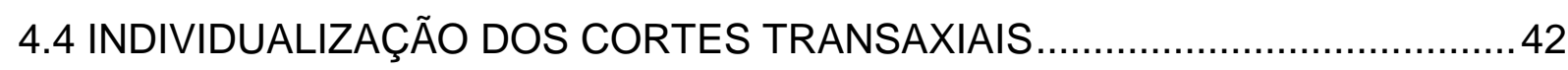

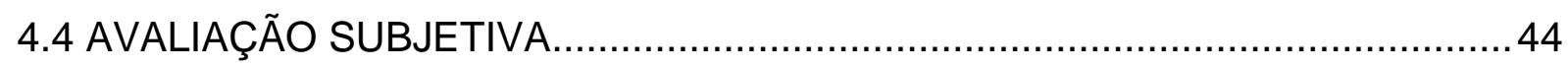

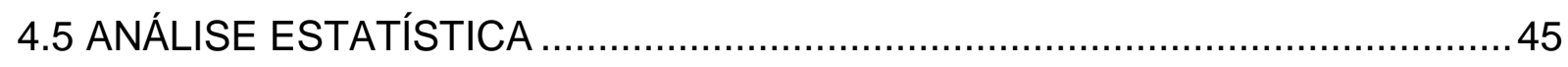

5 RESULTADOS

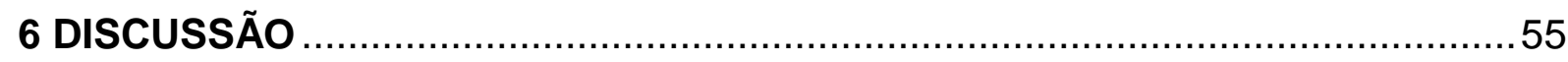

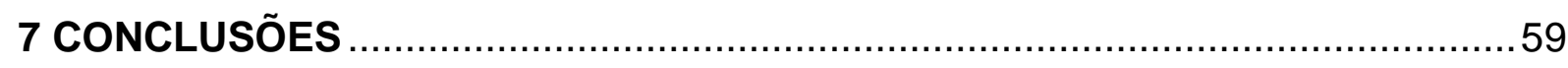

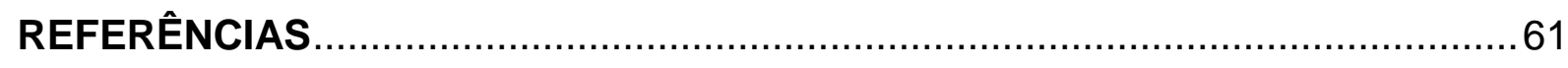

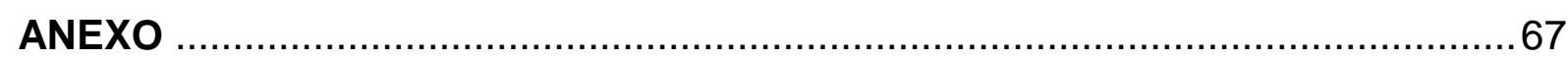





\section{INTRODUÇÃO}

As adaptações estruturais e funcionais de tecido ósseo e tecidos moles na maxila e mandíbula ocorrem após exodontias e podem influenciar diretamente as alternativas terapêuticas (Akca; Iplikcioglu, 2001).

As mandíbulas severamente reabsorvidas consideradas como atrésicas ou atróficas são de difícil tratamento, comumente problemas como retenção da prótese, intolerância à carga pela mucosa, dor, dificuldades com alimentação e fala são frequentes; contudo o sucesso do tratamento é considerado um desafio para os protesistas (Stellingsma et al., 2004).

$\mathrm{Na}$ implantodontia é de censo comum obter informações sobre o tecido ósseo remanescente, tanto do ponto de vista quantitativo como também de sua qualidade óssea; a partir dos exames radiográficos têm- se informações sobre as áreas de interesse e as estruturas anatômicas contíguas (Costa et al., 2010).

A quantidade óssea refere-se a altura e espessura do rebordo residual; a qualidade óssea depende da espessura do osso cortical, tipo do osso trabecular e seu grau de mineralização, são considerados fatores chave da osseointegração (Valiyaparambil et al., 2012).

A Tomografia Computadorizada (TC) é bem aceita na área médica por fornecer informações do tecido ósseo requerido, parâmetros como unidades de Hounsfield (UH) referem-se à valores absolutos derivados do grau de atenuação de raios- $\mathrm{X}$ e atribui aos pixels das imagens a densidade do tecido (White et al., 2008).

Com a evolução dos sistemas tomográficos, houve a melhora da qualidade das imagens e, portanto, no detalhamento das estruturas anatômicas avaliadas (Costa et al., 2010).

Os componentes dos tomógrafos computadorizados (gantry, computador e workstation) permitem as conversões digitais dos dados adquiridos na forma de algoritmos, que transformados em pixels (picture elements) podem ser reformatados, transferidos ou agrupados em modelos tridimensionais por meio de voxels (volume elements) (Costa et al., 2010).

Com o advento da Tomografia Computadorizada de Feixe Cônico (TCFC) também tornou possível visualizar o complexo maxilofacial e a relação das estruturas anatômicas em três dimensões (Sukovic, 2003). 
A imagem tomográfica é visualizada e estudada a partir dos programas de planejamento que permitem a visualização da área de interesse em três planos: sagital, axial e coronal; a partir dos cortes axiais são realizadas reformatações em cortes transaxiais ou oblíquos e panorâmicos (Costa et al., 2010).

A TCFC está amplamente aceita como uma ferramenta precisa para o planejamento de implante dental por ter vantagens como ampla disponibilidade aos cirurgiões-dentistas e os custos reduzidos comparados à TC (Parsa et al., 2013).

Vários autores têm estudado a relação entre a densidade óssea e a taxa de sobrevida de implantes. A densidade do osso disponível em um sitio desdentado é um fator determinante no plano de tratamento, projeto do implante, abordagem cirúrgica, tempo de cicatrização e carga inicial progressiva sobre o osso durante a reconstrução protética. A média de sobrevida do implante tem sido associada à sua posição relativa no arco (González-García; Monje, 2013; Resnik et al., 2008).

A Estabilidade primária de um implante é o fator chave para o sucesso em longo prazo de uma osseointegração, instabilidades induzem micromovimentos durante a cicatrização óssea que pode lesar à uma área fibrosa ao redor do implante causando o insucesso deste (Lioubavina-Hack et al., 2006; Fuh et al., 2010).

A avaliação da densidade óssea tem sido uma área de interesse crescente, a relação entre $\mathrm{UH}$ e coeficientes de atenuação linear são difíceis de calcular. Alguns estudos revelam que a TCFC pode correlacionar a qualidade óssea com a estabilidade primária de implantes (Mah et al., 2010).

Vários autores têm relatado o uso de valores de intensidade de pixel ou voxel provenientes da atenuação de raios- $X$ da TCFC como uma medida para avaliar a densidade óssea radiográfica (Silva et al., 2012; Razi et al., 2014). 


\section{REVISÃO DA LITERATURA}

\subsection{Planejamentos para Implantes}

Acredita-se que o sucesso do procedimento cirúrgico de implantes depende de avalições pré-operatórias que podem determinar a viabilidade da fixação de implantes, como a avaliação radiográfica inicial, histórico médico geral e exame clínico criterioso. Diante de exames radiográficos iniciais pode-se ter informações morfológicas da área proposta, presença ou ausência de patologias, visualização de estruturas anatômicas adjacentes como seio maxilar, fossa nasal, canal incisivo, canal da mandíbula e, forame mentual. As imagens radiográficas devem permitir a avaliação quantitativa do sítio do implante como volume ósseo (altura, espessura) como também a qualidade óssea, como a densidade óssea das corticais e osso trabecular. Fatores intrínsecos à biocompatibilidade do material do implante como características da superfície do implante também são responsáveis pelo êxito do tratamento (Frederiksen, 1995; Scarfe et al., 2006; Turkyilmaz et al., 2007; Valiyaparambil et al., 2012; Benavides et al., 2012).

Kobayashi et al. (2004) afirmaram que o objetivo do planejamento pré-operatório em implantodontia consiste em determinar o número e tamanho ideal de implantes para o tratamento restaurador, diante disso as imagens radiográficas são essenciais para avaliação óssea, com o auxílio da radiografia panorâmica considerado o exame inicial por fornecer de informações relevantes como a ampla visualização das arcadas e estruturas anatômicas importantes; porém exames complementares para a região são necessários para melhores detalhes do sítio do futuro implante.

As dimensões de corticais ósseas expressa por largura e altura são sempre avaliadas pelo cirurgião antes da inserção do implante por meio de inspeção clínica e exames por imagem. Entretanto, as medidas de densidade óssea alveolar do futuro sítio do implante são utilizadas com menor frequência. No entanto, avaliar a densidade óssea pré-operatória continua a ser um fator importante, assim como avaliar a microestrutura do osso trabecular, visto que determina a força de resistência, osseointegração e cicatrização óssea do local; portanto parâmetros que normalmente são responsáveis pela taxa de estabilidade primária que o implante pode alcançar (Turkyilmaz et al., 2008; Ibrahim et al., 2014). 


\subsection{Tomografia Computadorizada e Densidade Óssea}

A Tomografia Computadorizada (TC) é o exame radiográfico digital que não apresenta ampliações, ausência de distorções e, permite informações relativas à altura, espessura e formato de tecido ósseo, além da análise de densidade óssea por meio da escala de Hounsfield (Costa et al., 2010).

$\mathrm{Na}$ TC cada tipo de tecido apresenta um coeficiente de atenuação linear, fornecendo dados numéricos dentro de uma escala denominada Unidades Hounsfield (U.H). Por convenção, a água é referenciada pelo número 0 , o ar pelo $1000 \mathrm{UH}$, osso cortical por + 1000- $1600 \mathrm{UH}$ e o osso trabecular valores menores. Para a densidade óssea, os valores de U.H podem ser convertidos em valores de densidade mineral óssea. No entanto, o maior risco à alta exposição de radiação em comparação com as outras modalidades continua a ser a principal preocupação para a área odontológica (Frederiksen, 1995; Turkyilmaz et al., 2007).

Misch (1989), propôs quatro grupos de densidade óssea com base nas características macroscópicas dos ossos cortical e trabecular, sendo D1 o tipo homogêneo de grande resistência, o mais frequentemente encontrado em mandíbulas nas regiões anteriores com reabsorção moderada a severa; D2 caracterizado pela combinação de osso cortical denso à poroso e na crista óssea osso trabecular desorganizado, ocorre mais frequentemente em região anterior de mandíbula e, seguido por posterior de mandíbula; D3 composto por espessura fina de osso cortical e osso trabecular poroso na crista óssea, frequentemente encontrado em regiões anterior e posterior de maxila; D4 tem pouca densidade e pouco ou nenhuma cortical na crista óssea, frequentemente encontrada em região posterior de maxila e raramente observada em mandíbula. 
Figura 2.1- Classificação de Densidade Óssea segundo Misch (2008)
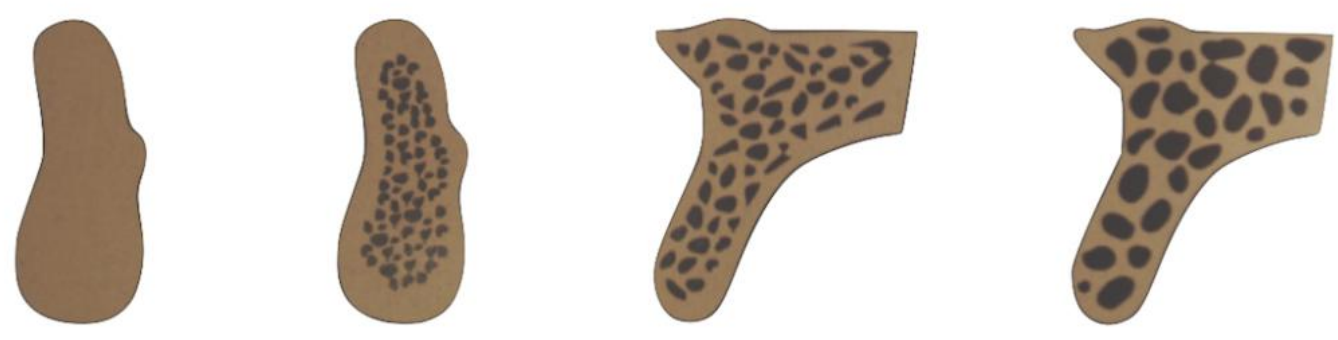

Os componentes dos tomógrafos computadorizados (Gantry, computador e workstation) permitem um trabalho único e exclusivamente digital dos dados adquiridos, na forma de algoritmos, que transformados em pixels (Picture elements) podem ser reformatados, transferidos ou agrupados em modelos tridimensionais por meio de voxels (volume elements). Na imagem tomográfica a dimensão do voxel é determinado pelo tamanho de cada pixel, ou seja, o elemento individual de uma imagem de TC é chamado voxel, para cada valor referido é observado a densidade da imagem nesse ponto. O UH varia de -1000 (ar) para 3000 (esmalte), cada nível corresponde à atenuação de feixe de raios X (Frederiksen, 1995; Resnik et al., 2008).

O conhecimento do valor absoluto de UH como uma medição quantitativa da densidade óssea pode ser útil como uma ferramenta de diagnóstico. Pode proporcionar ao cirurgião dentista uma avaliação objetiva da densidade óssea, o que pode resultar em modificação de técnicas cirúrgicas ou extensão de tempo de cicatrização, especialmente em situações de suspeita de má qualidade óssea (Shapurian et al., 2006).

Turkyilmaz et al. (2007) demonstraram as variações de densidade óssea em sítios de implantes a partir da TC, notaram que há diferenças entre as 4 regiões de mandíbulas, sendo que a região anterior de mandíbula apresentou valores mais altos UH, seguido por região anterior de maxila, região posterior de mandíbula e por último a região posterior de maxila com valores menores de UH.

Turkyilmaz et al. (2008) sugerem que a TC é uma ferramenta útil para avaliar a densidade óssea de futuros sítios de implantes, as informações quantitativas e objetivas sobre as áreas receptoras são parâmetros que podem determinar a qualidade óssea e predispõe a possível falha em um osso de baixa densidade. 


\subsection{Tomografia Computadorizada por Feixe Cônico (TCFC)}

Com a constante evolução de aparelhos tomográficos, a Tomografia Computadorizada de feixe cônico (TCFC) tornou-se a substituta para exames tomográficos de alto contraste para avalição de estruturas ósseas da região maxilofacial (Pauwels et al., 2015).

A Tomografia Computadorizada de feixe cônico (TCFC) é uma técnica de imaginologia digital que permite gerar cortes multiplanares de uma região de interesse e reconstrução de imagens em três dimensões, por meio de feixes rotacionais de raios $X$ em forma de cone, oriundos por meio de uma série de algoritmos matemáticos (Scarfe et al., 2006)

A partir das gerações de imagens tridimensionais, a TCFC desempenha um papel importante na análise de estruturas de tecidos duros na região maxilofacial, uma vez que proporciona imagens de alta resolução. Quando comparada com à TC, diversas vantagens à TCFC foram relatadas, tais como a redução do tempo de exposição, entre 10-70 segundos; dose de radiação absorvida pelo paciente, cerca de até 15 vezes menos; custo relativamente baixo, tamanho conveniente, e facilidade de operação (Scarfe et al., 2006; Liang et al., 2010; Ballrick et al., 2008).

$A$ TCFC gera feixes de raios $X$ em forma de cone e as imagens são adquiridas por rotação do equipamento e por um intensificador de imagem (detector de imagem) resultando razoavelmente baixos níveis de doses de radiação. Durante a rotação múltiplas imagens multiplanares sequenciais do campo de visão são adquiridos em um arco completo ou parcial; a tecnologia proporciona a reconstrução Tridimensional (3D) do complexo maxilofacial com mínimo grau de distorção e alta resolução de imagem (Arai et al., 1999; Chan et al., 2010; Scarfe et al., 2006).

O conjunto de dados da imagem tomográfica é representado pelo voxel, o qual determina a resolução da imagem em uma unidade de volume, ou seja, a partir de cubos isotrópicos de mesma dimensão, ao contrário da TC que são definidos como cubos anisotrópicos, ou seja com dimensões diferentes (Scarfe et al., 2006). 
O FOV (Field of view) está relacionado com o volume do equipamento e pode ser variável de acordo com o equipamento de Tomografia Computadorizada por feixe Cônico (TCFC) e depende do tamanho e forma do detector, geometria de projeção do feixe e a capacidade de colimação do feixe, o que difere entre os equipamentos (Suomalainen et al., 2008).

O uso da tecnologia de Tomografia Computadorizada de Feixe Cônico (TCFC) na prática clínica é comumente utilizada para avaliação da qualidade óssea, principalmente para o planejamento pré-operatório de implantes; oferece algumas vantagens para a imaginologia em comparação com a Tomografia Computadorizada (TC) como: redução do tamanho da área irradiada pela colimação de feixes de raios-X à uma área de interesse, ou seja, pode-se ajustar à área de interesse clínico (Scarfe et al., 2006; Pawels et al., 2015).

A Tomografia Computadorizada (TC) e Tomografia Computadorizada por feixe cônico (TCFC) foram comparadas na avaliação das dimensões do sitio do implante e as medidas de TCFC encontradas foram mais precisas do que as medições de TC (AlEkrish; Ekram, 2011; Kobayashi et al., 2004; Loubele et al., 2008; Suomalainen et al., 2008).

Alguns estudos correlacionam os valores absolutos de $\mathrm{HU}$ em Tomografia Computadorizada aos níveis de escalas de cinzas na Tomografia Computadorizada por Feixe Cônico (Naitoh et al., 2010; Nomura et al., 2010; Mah et al., 2010).

Há uma controvérsia na literatura sobre o uso de HU em TCFC visto que a escala de Hounsfield foi projetada originalmente para TC. Devido a necessidade de calibração adequada e a utilização do coeficiente de atenuação, esta escala não é compatível com TCFC (Norton; Gamble, 2001; Nackaerts et al., 2015; Isoda et al., 2012; González-Garcia; Monje, 2013; Samilov et al., 2014; Cortes et al., 2015).

Estudos recentes relataram inconsistências das medições de TCFC, devido ao espalhamento de raios $\mathrm{X}$ e artefatos que podem influenciar os valores de densidade óssea. Esses fatores podem resultar em desvios das medições, superestimar a densidade e aumentar a medida linear (Molteni, 2013; Ibrahim et al., 2014). 


\subsection{Qualidade óssea}

Recentemente a quantidade e qualidade óssea têm sido sugeridas como um dos principais fatores que influenciam o sucesso do tratamento de implantes (Goiato et al., 2014; Pawels et al., 2015).

Lindh et al. (2004) enfatizaram que a densidade mineral óssea (DMO) e qualidade óssea não são sinônimos. A qualidade óssea engloba diferentes fatores como o tamanho do osso, da arquitetura e orientação $3 D$ da trabécula $e$ propriedades da matriz. A qualidade óssea não é apenas uma questão de conteúdo mineral, mas também de estrutura. A Quantidade óssea é definida a partir da altura e espessura, é dividida em cinco grupos (de mínima a severa), com base na forma da mandíbula e as diferentes taxas de reabsorção ósseas residuais oriundas de exodontias.

A reabilitação oral a partir de um implante dental em um osso de má qualidade é a maior preocupação contra falhas, deve-se ter cuidado quando o sítio ósseo é de baixa densidade (tipo IV) e de osso de alta densidade (tipo I) para evitar o aquecimento do tecido ósseo durante a perfuração (Alsaadi et al., 2008).

Boa qualidade óssea é frequentemente citada como um pré-requisito para a estabilidade primária do implante, mas o conceito de qualidade óssea e como pode ser avaliada não é claramente definida na literatura. O termo abrange diversos aspectos da fisiologia do osso, grau de mineralização e as propriedades estruturais (Bergkvist et al., 2010; Pawels et al., 2015).

A avaliação do tecido ósseo pré-operatório atua também como uma ferramenta de prognóstico para prever a probabilidade de sucesso ou fracasso, já que as características do tecido ósseo de qualidade, quantidade e densidade são consideradas importantes no que diz respeito aos resultados do tratamento (Friberg et al., 1995).

Baseado na classificação subjetiva de Lekholm e Zarb (1985) a densidade óssea é classificada de acordo com formas anatômicas de mandíbulas e maxila utilizando parâmetros quantidade e qualidade óssea, sendo que esta é dividida em quatro grupos de acordo com a proporção e estrutura entre tecido ósseo compacto e trabecular. 
A qualidade óssea é classificada em quatro grupos: grupos de 1-4 ou tipo I a IV. Tipo I ou D1: osso compacto e homogêneo;

Tipo II ou D2: espessa camada de osso compacto circundando núcleo de osso trabecular denso

Tipo III ou D3: fina camada de osso cortical circundando núcleo de osso trabecular denso com resistência favorável

Tipo IV ou D4: fina camada de osso cortical circundando núcleo de osso trabecular de baixa densidade.

Figura 2.2- Classificação de Qualidade Óssea segundo Lekholm e Zarb (1985),

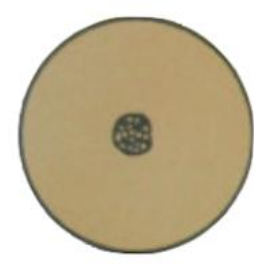

Tipo I

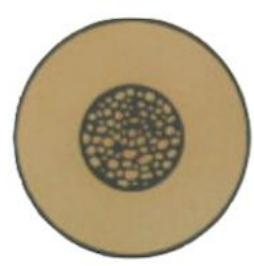

Tipo II

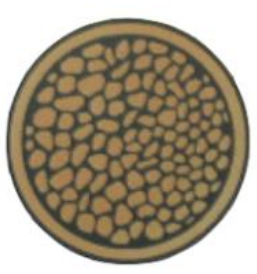

Tipo III

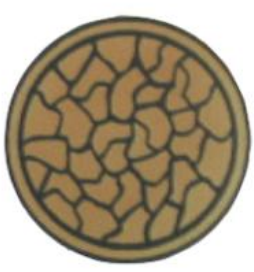

Tipo IV

Norton e Gamble (2001) estudaram como o tipo de arquitetura óssea influenciam a capacidade de suporte de carga e tem sido demonstrado que quanto mais pobre a qualidade óssea, elevadas taxas de insucesso são encontradas. A partir de imagens obtidas por meio de TC da maxila e mandíbula, determinaram os valores quantitativos para a densidade mineral óssea, em Unidades Hounsfiled (HU), para quatro diferentes regiões dos maxilares: $(>+850$ H.U) mandíbula anterior; (+500 até +800) mandíbula posterior e maxila anterior e $(0$ até +500$)$ maxila posterior. Encontraram uma forte correlação entre os valores da densidade óssea em $\mathrm{HU}$ e a qualidade subjetiva descrita por Lekholm e Zarb (1985). Os autores adotaram uma nova classificação de qualidade óssea visto que não houve diferenças significativas entre os tipos II e III, portanto houve a fusão entre eles. 
Trisi e Rao (1999) correlacionaram a avaliação da qualidade óssea entre a histomorfometria do volume ósseo trabecular e, concluíram que há correlação para densidades classificadas como D1 e D4, utilizando a classificação Misch (1989) com a percepção táctil, houve a percepção subjetiva de resistência à perfuração; entretanto, para as classes intermediárias D2 e D3 foi difícil a distinção.

Tozog lu e Çakur (2014) compararam as alterações morfológicas na mandíbula entre dentados e desdentados utilizando de imagens de TCFC e concluíram que a morfologia do osso basal da mandíbula altera como consequência da perda dental, o índice de qualidade óssea é dada pela proporção entre tecido ósseo cortical e trabecular e são representados por 4 tipos, sendo osso cortical homogêneo; osso cortical espesso com uma cavidade no osso trabecular; osso cortical de fina espessura com osso trabecular denso de boa resistência e osso cortical de fina espessura com baixa densidade óssea trabecular e baixa resistência. A TCFC foi considerada uma boa ferramenta para visualização desses casos.

A reabilitação oral a partir de um implante dental em um osso de má qualidade é a maior preocupação contra falhas, deve-se ter cuidado quando o sítio ósseo é de baixa densidade (tipo IV) e de osso de alta densidade (tipo I ) para evitar o aquecimento do tecido ósseo durante a perfuração (Alsaadi et al., 2008).

Além disso, estudos recentes sugerem que o uso adequado de sistemas de perfuração e escolha de geometrias de implante para a região posterior da maxila e da mandíbula com o osso de baixa densidade melhora a estabilidade primária de implantes dentários e aumenta a taxa de sobrevivência; concluíram que os implantes com superfícies tratadas inseridos em osso tipo IV pode ter uma melhor taxa de sobrevivência em relação aos implantes usinados (Türkyilmaz et al., 2008; Goiato et al., 2014).

Estudos recentes avaliaram implantes colocados em osso de má qualidade óssea, com cortical óssea fina e trabeculado de baixa densidade (Tipo IV), mostraram uma maior chance de falha em comparação com os outros tipos de ossos. Este osso de baixa densidade é frequentemente encontrado em região posterior de maxila e vários estudos relatam altas taxas de falha de implantes e valores de estabilidade primária mais fracos nessas regiões (Bryant, 1998; Peñarrocha et al., 2004; Drage et al., 2007; Pawels et al., 2015). 
Cortes et al. (2015) avaliaram a densidade óssea alveolar em sítios de implantes a partir de imagens obtidas pela Tomografia Computadoriza de Feixe Cônico (TCFC) como densidade óssea radiográfica e encontraram forte correlação entre medidas morfométricas de Microtomografia Computadorizada (micro-TC) e corte histológico.

A técnica de micro-CT tornou-se padrão ouro para avaliação morfológica do osso trabecular e microestruturas, porém tem como limitação o tamanho da área exposta, somente para pesquisas in-vitro (Gonzáles-Garcia; Monje, 2013).

Desta forma, é de extrema importância padronizar um sistema de classificação consistente para as características do tecido ósseo, bem como a discrição de um método de avaliação do tecido ósseo e para isso obter melhor precisão de diagnóstico (RibeiroRotta et al., 2011). 



\section{PROPOSIÇÃO}

- Avaliar e comparar os níveis de cinza dos voxels de imagens obtidas por tomografia computadorizada de feixe cônico de rebordos mandibulares reabsorvidos com o uso de três programas para diagnóstico e planejamento de implantes.

- Correlacionar a intensidade de pixel (IP) com a classificação subjetiva de acordo com Índice de Qualidade Óssea (IQO). 



\section{MATERIAL E MÉTODOS}

O projeto foi submetido ao Cômitê de Ética em Pesquisa (CEP) da Universidade de São Paulo, o qual recebeu o número 1.070.765, em 20/05/2015 (Anexo A).

\subsection{Protocolo de aquisição das imagens}

As imagens digitais foram obtidas a partir do banco de dados do LAPI-FOUSP, onde foram estudados os níveis de cinza dos voxels obtidos de imagens digitais de mandíbulas atróficas. Utilizando o equipamento Gendex GXCB-500 (Gendex Dental Systems, Hatfield, PA, USA). Os protocolos de aquisição para TCFC no tamanho do voxel de $0,125 \mathrm{~mm}$, com tempo de aquisição de 23 segundos, regime de trabalho de 90-120 kVp e 3-8 mA, sensor Flat Panel de Silício Amorfo com área de $13 \mathrm{~cm} \times 13 \mathrm{~cm}$, volume de aquisição cilíndrico, 360 graus de rotação, 14 bits de profundidade de cinza (16.384 tons) e field of view (FOV) de $8 \mathrm{~cm}$ de altura $X 14 \mathrm{~cm}$ de diâmetro e posteriormente analisados nos programas de planejamento.

\subsection{Seleção da amostra}

As imagens possuem 8 demarcações fixadas com fios ortodônticos, denominadas de $\mathrm{C} 1$ a $\mathrm{C} 8$ (Corte 1, Corte 2, Corte 3 e assim sucessivamente) sendo quatro marcações nas regiões posteriores $(C 1, C 2, C 7$ e $C 8$ ) e 4 nas regiões anteriores ( $C 3, C 4, C 5$ e $C 6$ ), em regiões previamente determinadas para as avaliações. As marcações abrangem todo o contorno, da base ao limite mais superior da crista alveolar. 
Figura 4.1- Corte Axial das demarcações das 8 regiões

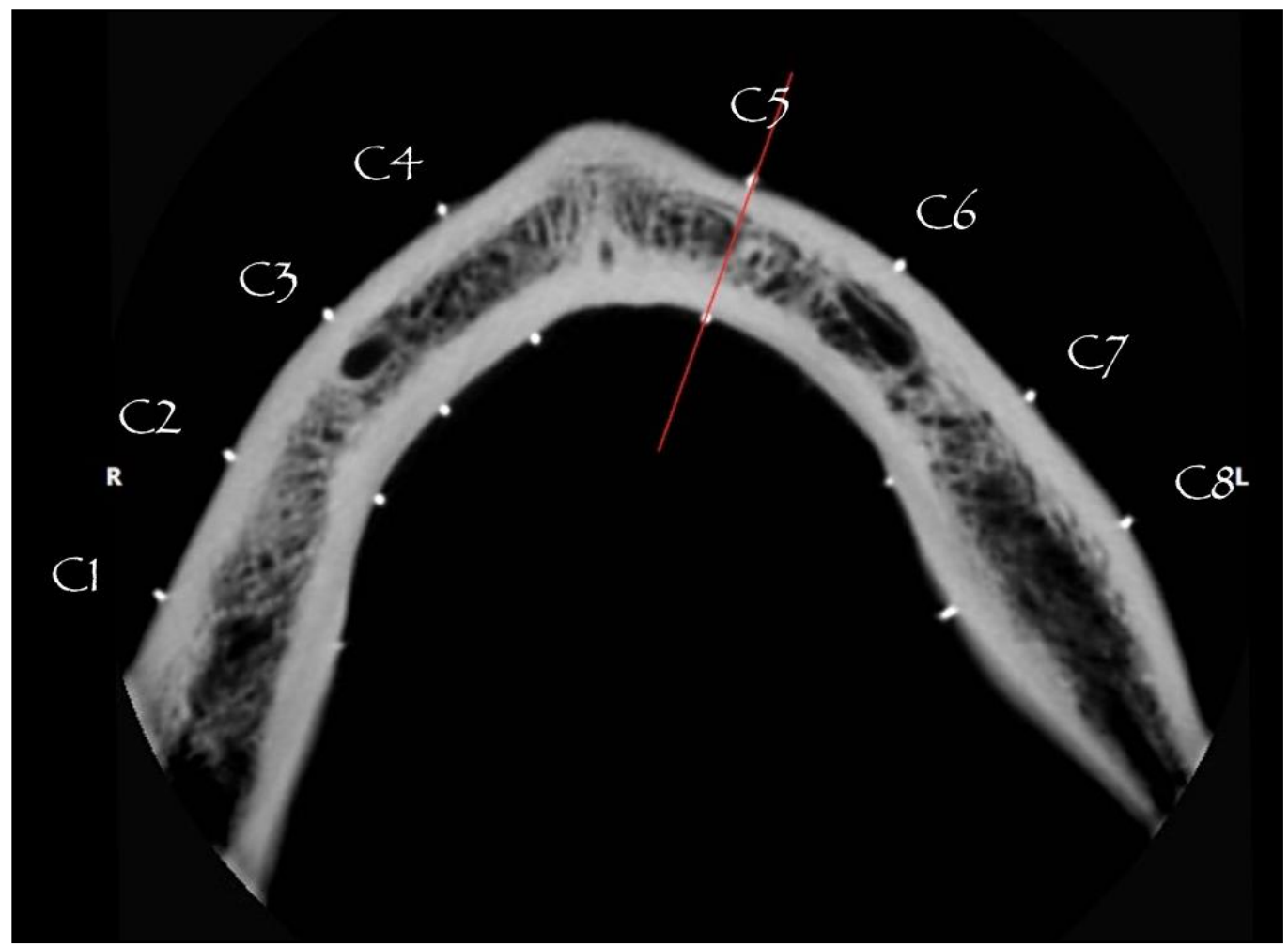

\subsection{Avaliação das imagens}

As imagens axiais foram geradas e salvas em formato DICOM (Digital Imaging and Communication in Medicine) e importadas pelos programa de planejamento: Xoran versão 5.0 (XR) (Xoran Technologies ${ }^{\circledR}$ Inc, Ann Harbor, MI, USA); Romexis (Planmeca,Finland) e OsiriX 1.2 (OX) (Pixmeo ${ }^{\circledR}$, Genebra, Suiça). Em cada um dos programas o corte axial foi utilizado para demarcar o arco de referência para obtenção das reconstruções panorâmicas e transaxiais de cada uma das mandíbulas. 
Figura 4.2- Tela do programa Xoran

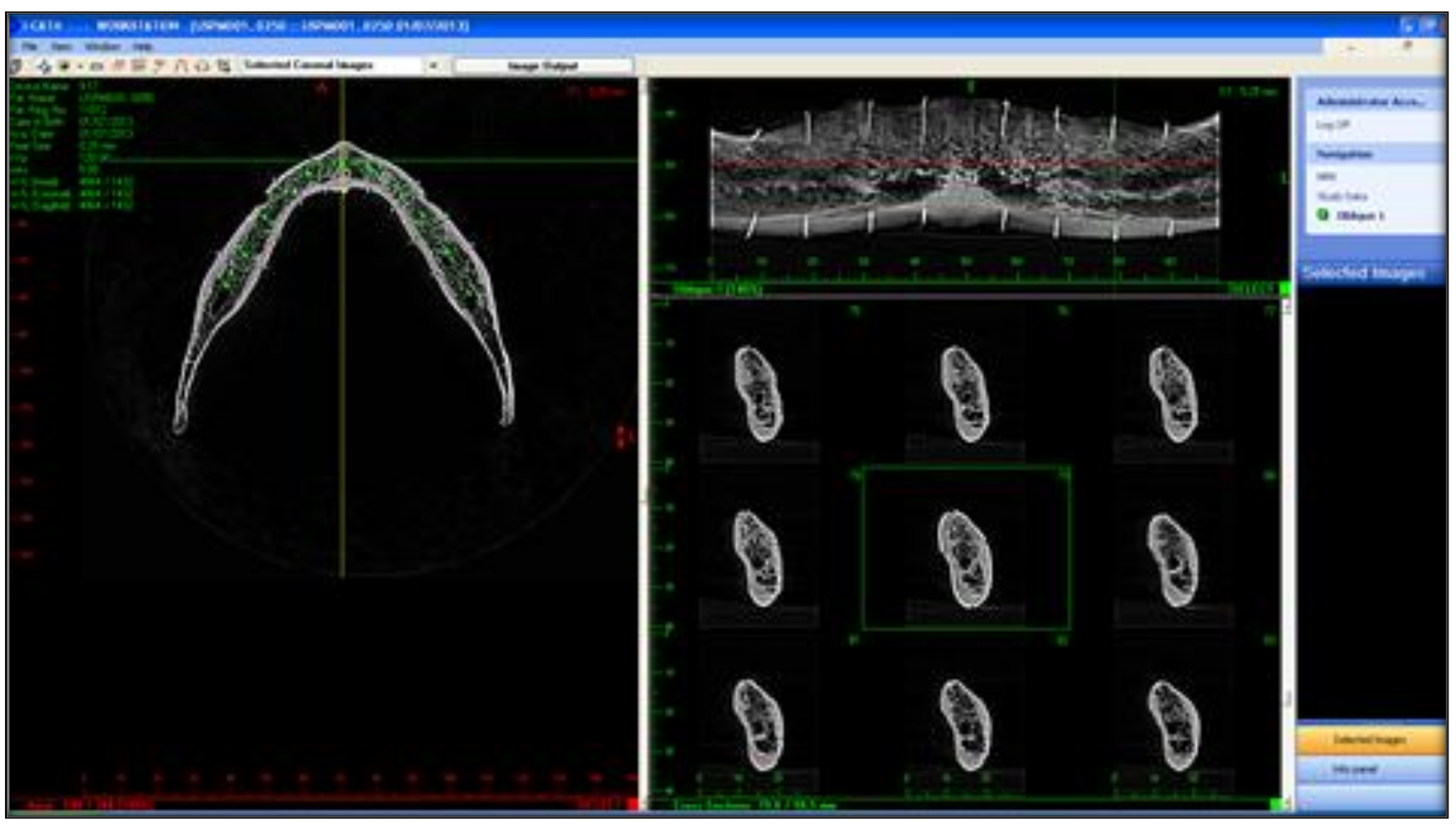

Figura 4.3- Tela do programa Romexis

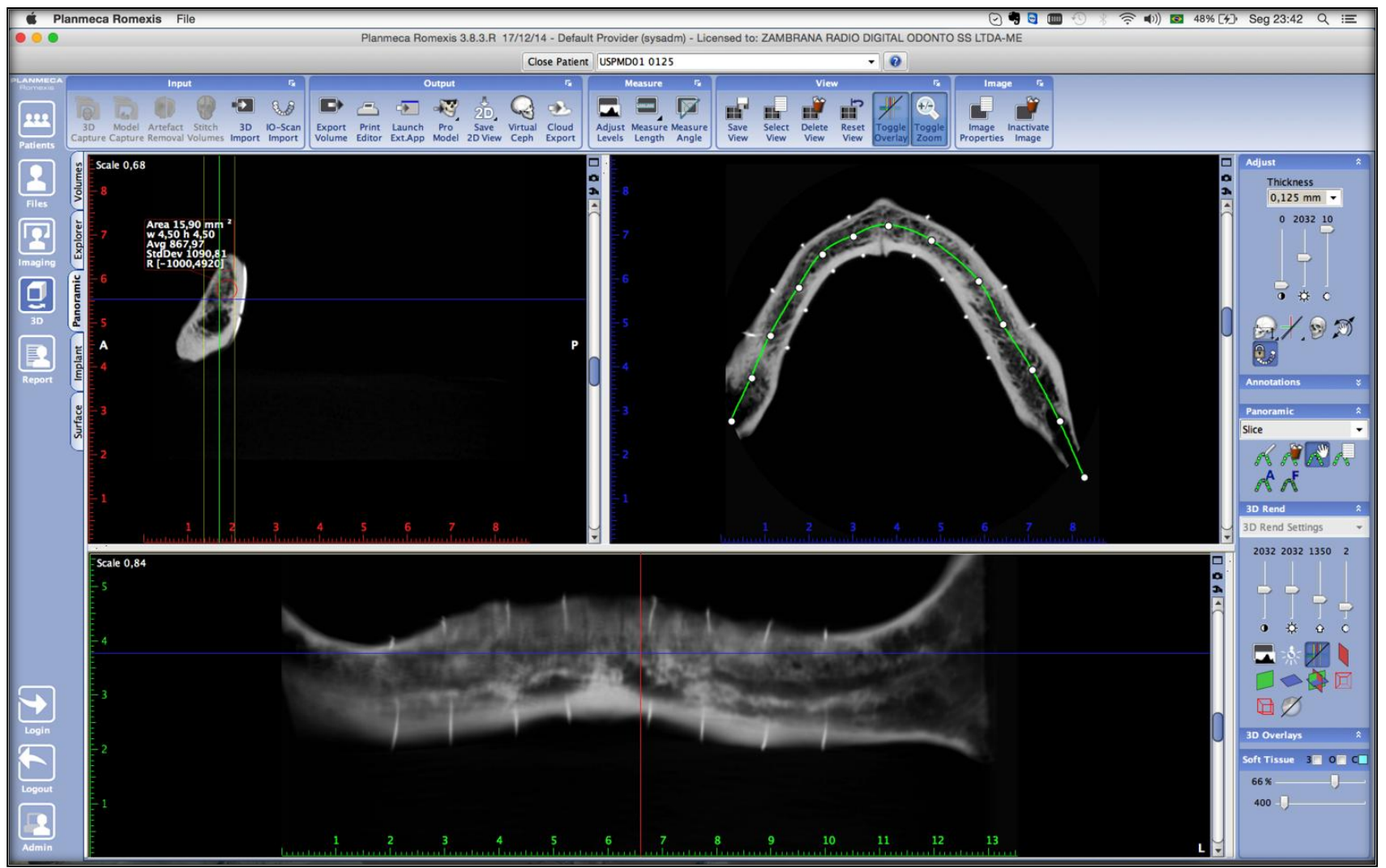


Figura 4.4- Tela do programa Osirix

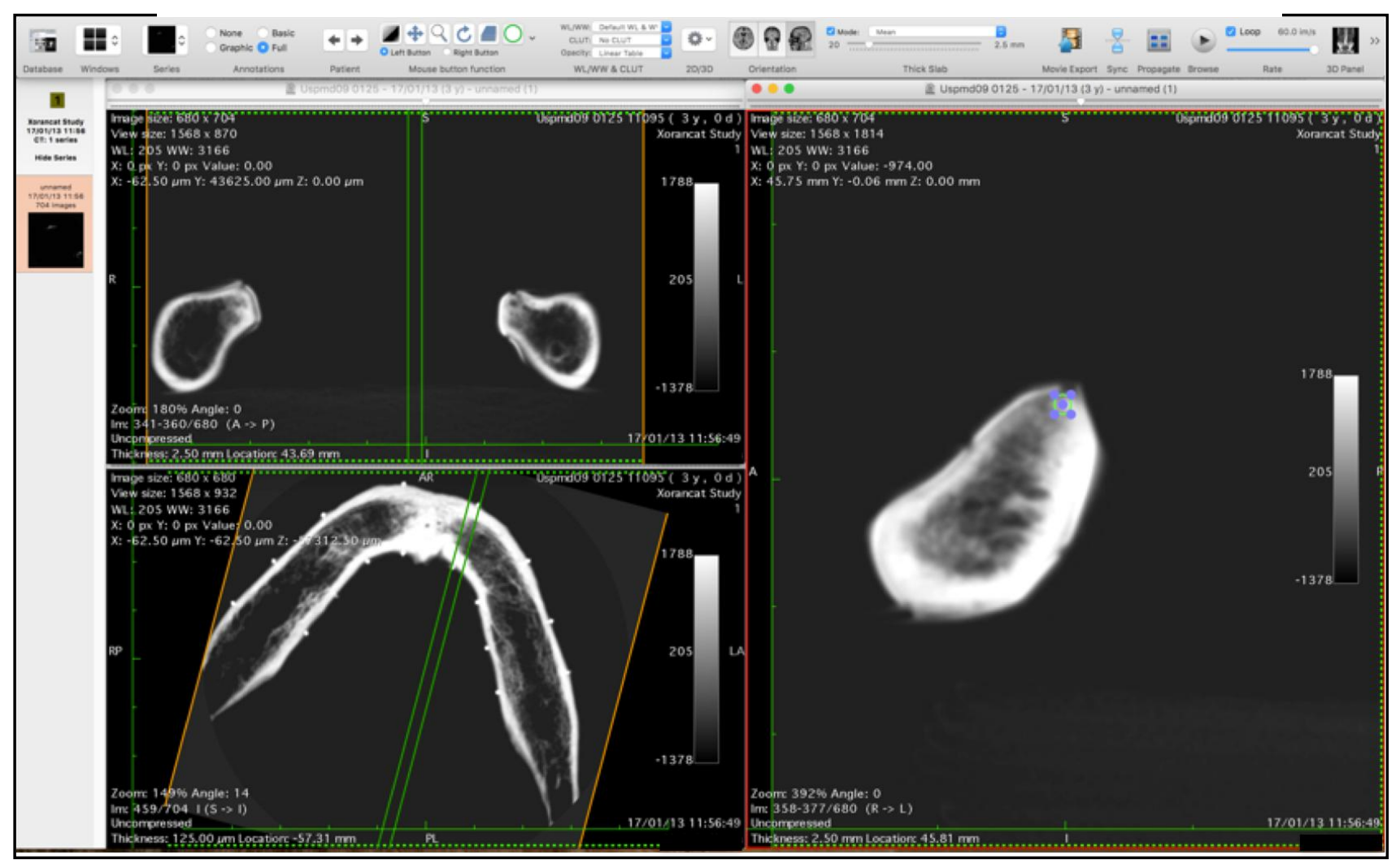

\subsection{Individualização dos cortes Transaxiais}

A partir dos cortes transaxiais foram criadas ROI (Região de interesse) para cada região correspondente, 4 corticais e 3 medulares. As quatro fendas de fio ortodôntico foram utilizadas como guia para as medidas.

Num total de 7 regiões, foram feitas as marcações com o ROI de $1,57 \mathrm{~mm}^{2} \mathrm{em}$ todas as regiões. 
Figura 4.5 - ROI de $1,57 \mathrm{~mm}^{2}$

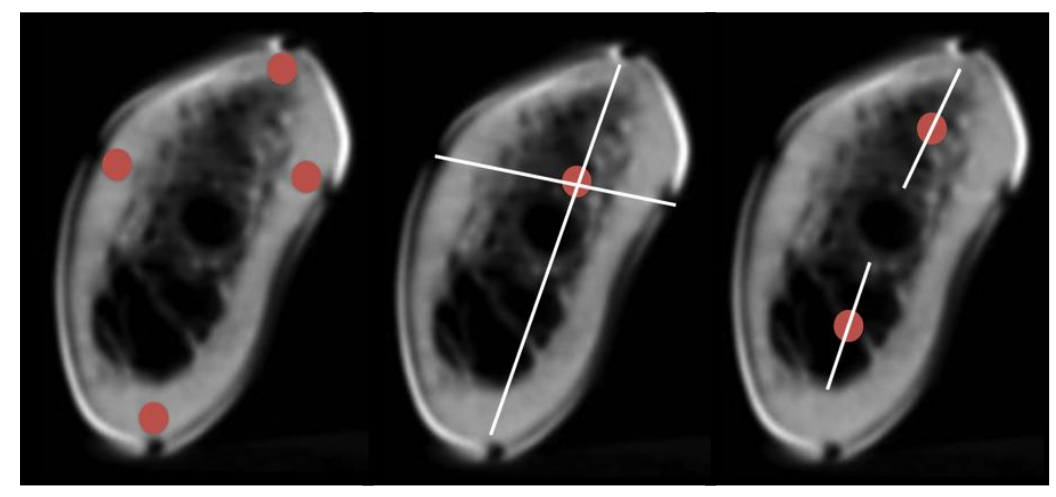

Figura 4.6- Cortes Transaxiais, com as demarcações de ROI de $1,57 \mathrm{~mm}^{2}$ em corticais de crista óssea e osso basal.

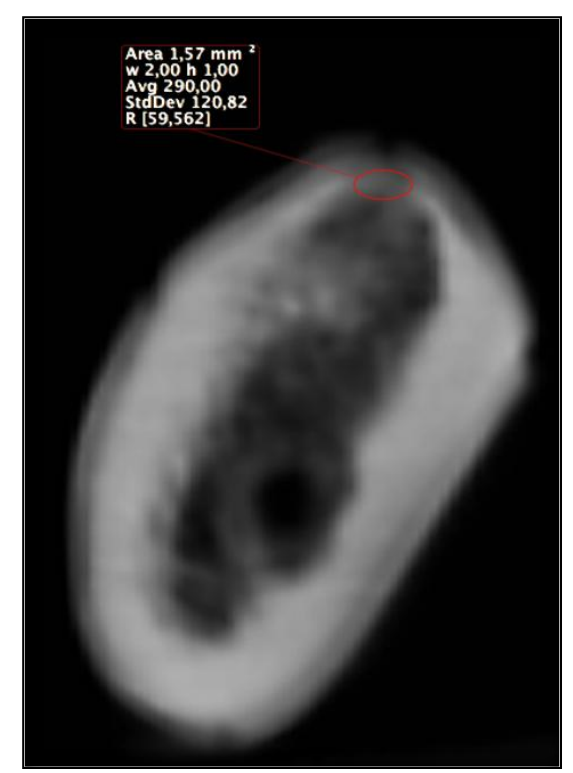

Com a ferramenta de ROI foi possível avaliar os valores de pixel da imagem ou Intensidade de pixel (IP) da área delimitada, a partir de valores de média, desvio padrão e amplitude que são dadas pela ferramenta. 


\subsection{Avaliação Subjetiva}

De acordo com Tozoğlu e Çakur, (2014) o Índice de Qualidade Óssea (IQO) descreve a qualidade do osso com base na quantidade e proporção de osso cortical e trabecular. As quatro classes são descritas como: I - Osso Cortical Homogêneo (Figura 4.7 a); II- Osso cortical espesso com cavidade no osso trabecular (Figura 4.7 b); III- Osso cortical de fina espessura e osso trabecular denso de boa resistência (Figura $4.7 \mathrm{c}$ ); IV- Osso cortical muito fino com baixa densidade óssea trabecular, baixa resistência (Figura 4.7 d)
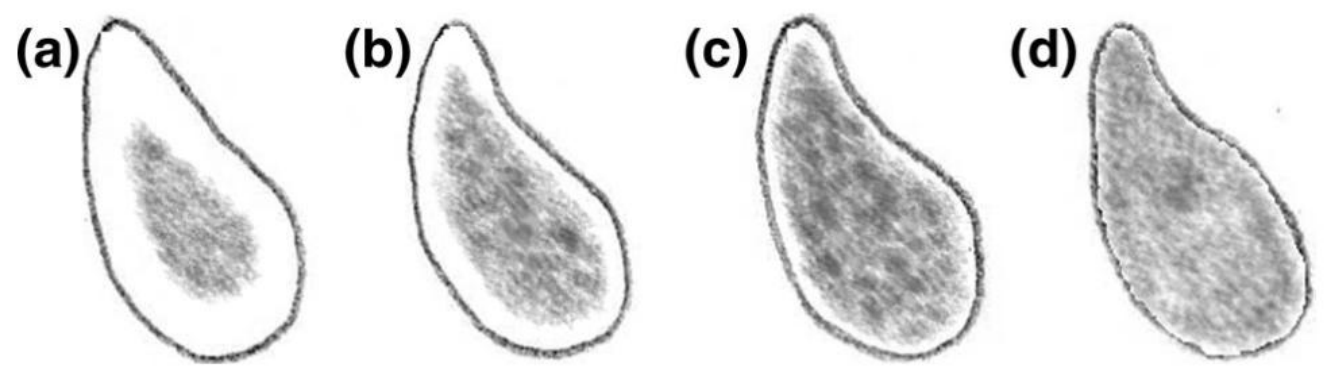

A partir dos cortes transaxiais de cada região foram feitas as análises subjetivas de qualidade óssea de acordo com o Índice de Qualidade Óssea.

As imagens foram avaliadas utlizando o monitor de Tela Retina Integrada (13,3 polegadas e resolução de $1680 \times 1050$ pixel) e correlacionadas com o índice de qualidade óssea cada corte transaxial por dois observadores em tempos diferentes T1 e T2).

Para análise de avaliação subjetiva de qualidade óssea houve o treinamento para os dois observadores. 


\subsection{Análise Estatística}

Os dados foram tabulados em planilhas do programa Microsoft Excel 2013 (Microsoft Corp., EUA) e posteriormente foi feito a análise estatística descritiva destes, sendo computados em tabelas e gráficos.

O IQO foi avaliado duas vezes pelo mesmo observador e uma vez por um segundo avaliador. A concordância intra e inter-observador foi avaliada pelo teste Kappa ponderado.

A diferença entre a frequência de IQO entre os programas foi testada com o teste qui-quadrado.

O teste estatístico usado foi a correlação de Spearman. A correlaçãoo entre IP e o IQO foi feita entre a média dos valores de IP das 7 regiões de cada corte e o tipo de IQO dado pelo avaliador. O nível de significância adotado foi de $5 \%(p<0,05)$.

As análises foram realizadas com o auxílio do programa Statistical Package dor Social Science (IBM SPSS Statistics Version 20.0 Chicago, IL, USA).

Para a análise de Kappa Ponderado as interpretações foram de acordo com a tabela (Figura 4.8).

Para a análise de Correlação de Spearman as interpretações foram de acordo com a tabela (Figura 4.9). 
Figura 4.8- Interpretação estatístico do Kappa Ponderado (Viera; Garrett, 2005)

\section{Interpretation of Kappa}

Poor Slight Fair Moderate Substantial Almost perfect

$\begin{array}{llllll}\text { Kappa } & 0.0 & .20 & .40 & .60 & .80\end{array}$

$\begin{array}{ll}\text { Kappa } & \text { Agreement } \\ <0 & \text { Less than chance agreement } \\ 0.01-0.20 & \text { Slight agreement } \\ 0.21-0.40 & \text { Fair agreement } \\ 0.41-0.60 & \text { Moderate agreement } \\ 0.61-0.80 & \text { Substantial agreement } \\ 0.81-0.99 & \text { Almost perfect agreement }\end{array}$

Figura 4.9- Interpretação estatístico de correlação de Spearman (Mukaka, 2012)

\begin{tabular}{|l|l|}
\hline Size of Correlation & Interpretation \\
\hline .90 to $1.00(-.90$ to -1.00$)$ & Very high positive (negative) correlation \\
\hline .70 to $.90(-.70$ to -.90$)$ & High positive (negative) correlation \\
\hline .50 to $.70(-.50$ to -.70$)$ & Moderate positive (negative) correlation \\
\hline .30 to $.50(-.30$ to -.50$)$ & Low positive (negative) correlation \\
\hline .00 to $.30(.00$ to -.30$)$ & negligible correlation \\
\hline
\end{tabular}




\section{RESULTADOS}

Diante dos dados estudados foram avaliadas 10 mandíbulas, com 8 cortes e 7 regiões em cada, ou seja, num total de 560 regiões. Foram agrupados de acordo com a localização anterior e posterior.

De acordo com a estatística descritiva, nota-se a frequência do Índice de Qualidade Óssea (IQO) nos dois momentos analisados (T1 e T2) pelo observador 1 (Tabela 5.1, Gráfico 5.1, Tabela 5.2 e Gráfico 5.2).

Tabela 5.1- Frequência de IQO para região anterior em porcentagem

\begin{tabular}{l|ccc}
\hline & Romexis & Xoran & Osirix \\
\hline Tipo I & 28,75 & 61,25 & 22,50 \\
Tipo II & 51,25 & 32,50 & 48,75 \\
Tipo III & 20 & 6,25 & 28,75 \\
Tipo II / III & 71,25 & 38,75 & 77,50 \\
Tipo IV & 0 & 0 & 0 \\
\hline
\end{tabular}

Gráfico 5.1- Frequência de IQO para região anterior

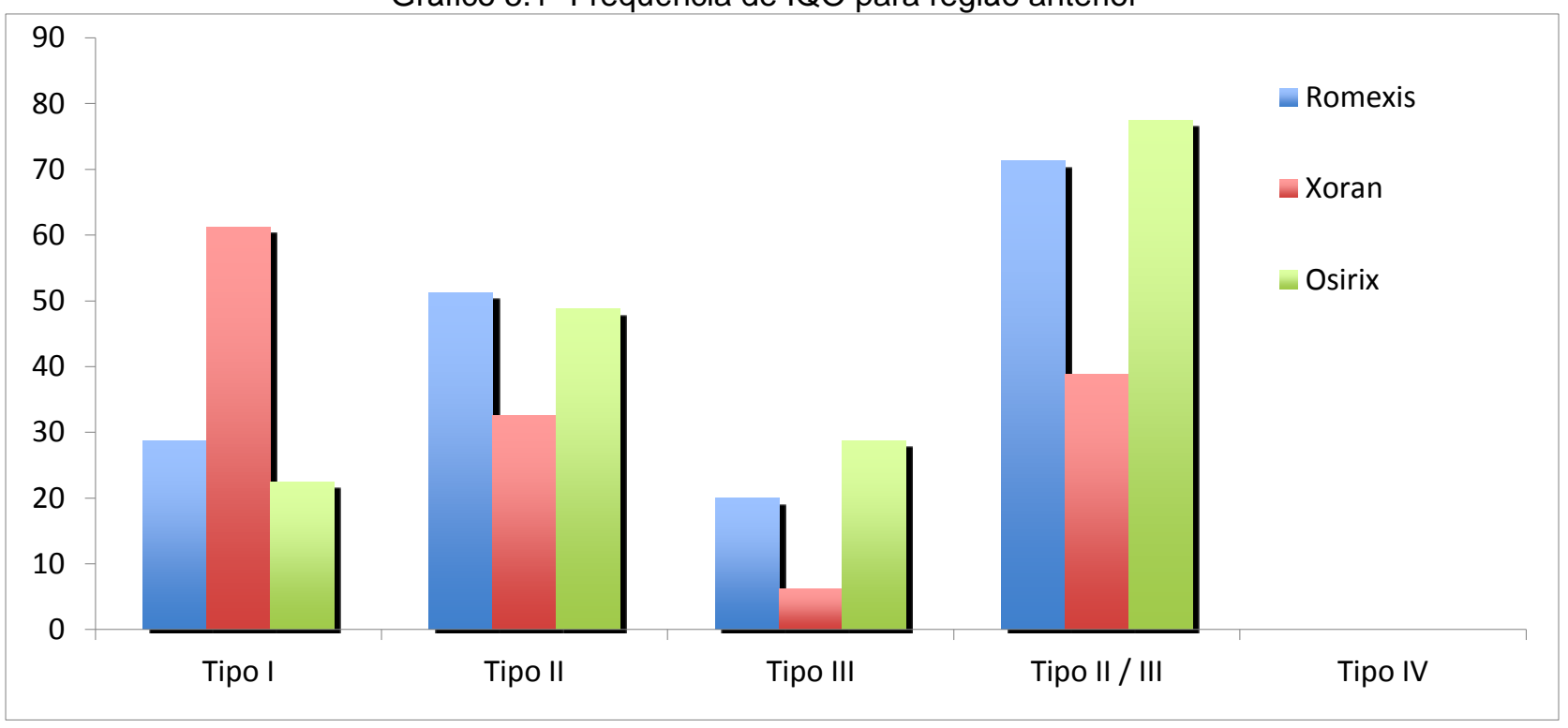


Tabela 5.2- Frequência de IQO para região posterior em porcentagem

\begin{tabular}{c|ccc}
\hline & Romexis & Xoran & Osirix \\
\hline Tipo I & 46,25 & 75 & 50 \\
Tipo II & 43,75 & 23,75 & 47,50 \\
Tipo III & 10 & 1,25 & 2,50 \\
Tipo II / III & 53,75 & 25 & 50 \\
Tipo IV & 0 & 0 & 0 \\
\hline
\end{tabular}

Gráfico 5.2: Frequência de IQO para região posterior

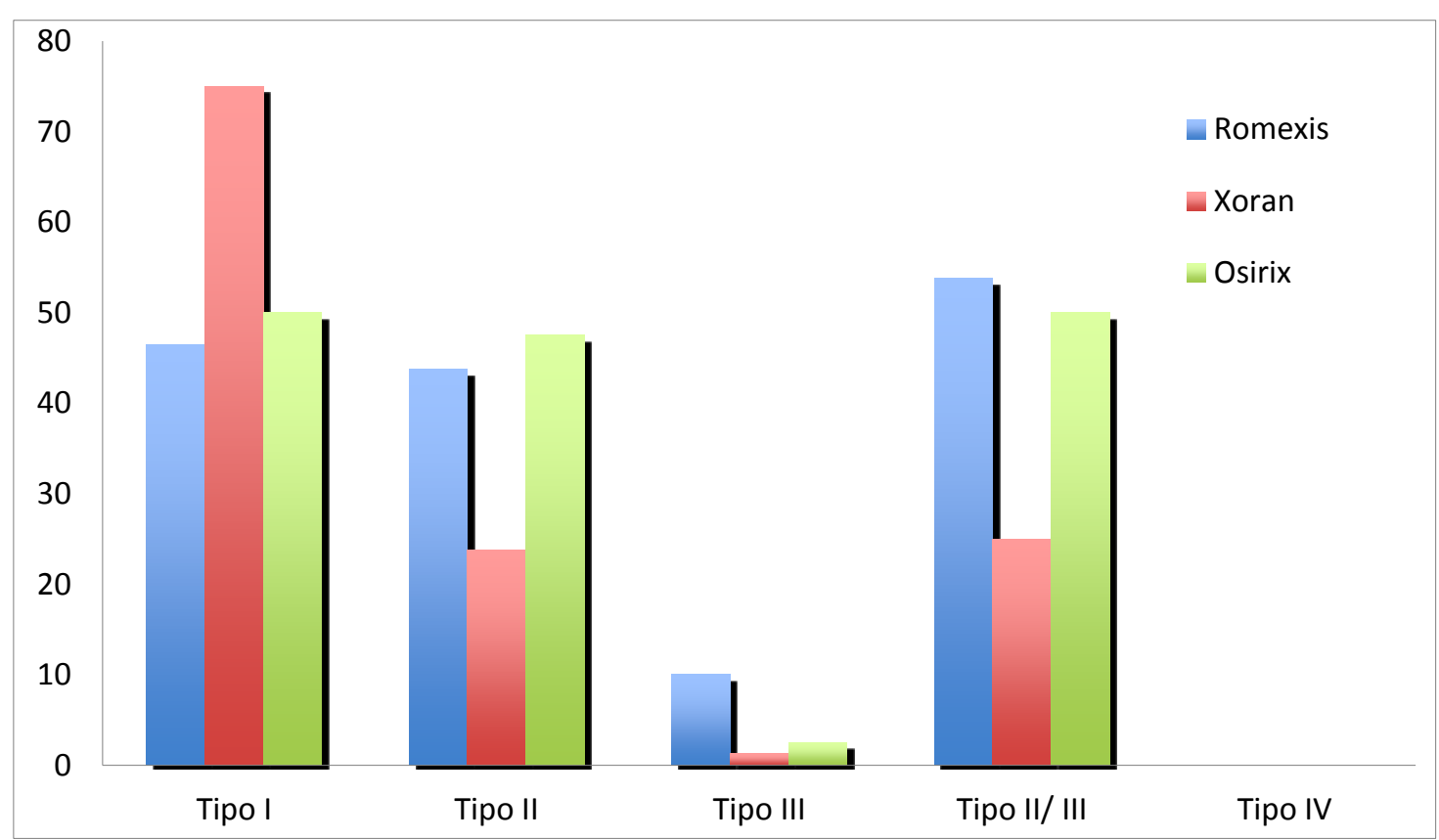

O Programa Xoran foi o que apresentou discrepâncias nas frequências das avaliações do Índice de Qualidade Óssea (IQO); já os programas Romexis e OsiriX apresentaram frequências semelhantes.

Para o agrupamento entre os tipos II e III segundo Norton e Gamble, 2001 os programas Osirix e Romexis ainda sim apresentam frequências semelhantes em comparação com o programa Xoran. 
Diante disso os programas Romexis e Osirix apresentaram avaliações mais próximas tendo em vista a acuidade do observador na escolha do Índice de Qualidade Óssea (IQO) (Gráfico 5.1 e 5.2).

A partir do teste estatístico Qui-Quadrado a diferença de frequência de IQO entre os 3 programas foram demonstrados nas tabelas 5.3, 5,4 e 5.5. Foi observado que não houve diferença significante entre as frequências de IQO entre os programas Romexis e OsiriX, entretanto houve diferença destes e o Xoran.

Tabela 5.3- Valores de freqüência entre observados e esperados para o teste qui-quadrado (Xoran X Romexis)

\section{Xoran x Romexis}

\begin{tabular}{|c|c|c|c|}
\hline & Observado $(\mathrm{n})$ & Esperado $(\mathrm{n})$ & Resíduo \\
\hline IQO1 & 68 & 24 & 44 \\
IQO2 & 11 & 38 & -27 \\
IQO3 & 1 & 18 & -17 \\
Total & 80 & & \\
\hline
\end{tabular}

Tabela 5.4- Valores de freqüência entre observados e esperados para o teste qui-quadrado (OsirX $x$ Xoran)

Osirix x Xoran

\begin{tabular}{|l|c|c|c|}
\hline & Observado & Esperado & Resíduo \\
\hline IQO1 & 24 & 68,0 & $-44,0$ \\
IQO2 & 41 & 11,0 & 30,0 \\
IQO3 & 15 & 1,0 & 14,0 \\
Total & 80 & & \\
\hline
\end{tabular}

\section{$p<0,0001$}

Tabela 5.5- Valores de freqüência entre observados e esperados para o teste qui-quadrado (OsirX $x$ Romexis)

Osirix x Romexis

\begin{tabular}{|c|c|c|c|}
\hline & Observado & Esperado & Resíduo \\
\hline IQO1 & 24 & 24,0 &, 0 \\
IQO2 & 41 & 38,0 & 3,0 \\
IQO3 & 15 & 18,0 & $-3,0$ \\
Total & 80 & & \\
\hline
\end{tabular}

$p=0,692$ 
A tabela 5.6 apresenta a avaliação do coeficiente das correlações de Spearman entre a Intensidade de pixel nos cortes ( $\mathrm{C} 1$ a C8) e o índice de qualidade óssea (IQO).

De acordo com Mukaka (2012), a interpretação do teste de correlação de Spearman foi de acordo com as especificações entre correlação muito alta, alta, moderada, baixa e desprezível.

Nota-se que o programa Romexis apresentou muito alta correlação entre Intensidade de Pixel (IP) e Índice de Qualidade Óssea (IQO) para a região C4; alta correlação para região C1 e C5 e moderada correlação para regiões C6 e C7.

O programa Osirix apresentou moderada correlação entre intensidade de Pixel (IP) e Índice de Qualidade Óssea (IQO) para regiões C1, C6 e C8.

Já o programa Xoran não apresentou correlação significativa entre as variáveis.

De acordo com Viera e Garrett (2005) a interpretação do coeficiente kappa foi de acordo com as especificações de $<0$, menor concordância; 0.01- 0.2, ligeira concordância; 0.21- 0.4, justa concordância; 0.41- 0.6, concordância moderada; 0.61- 0.8 , concordância substancial e 0.81 - 0,99 concordância quase perfeita.

A tabela 5.7 apresenta a concordância intra-observador para a variável IQO; nota-se que para o programa OsiriX houve uma justa concordância em C1, já em C4 houve uma concordância quase perfeita, em C5 houve moderada concordância, em C7 concordância justa e em C8 houve concordância moderada.

Para o programa Romexis notou-se que houve concordância substancial em C1 e concordância moderada em C2 e C3.

Já o programa Xoran não apresentou concordâncias significativas intraobservador.

A tabela 5.8 apresenta a concordância inter-observador para a variável IQO; nota-se que o programa OsiriX apresentou concordância substancial em C1 e C2, concordância moderada em C5 e concordância justa em C8.

Para o programa Romexis notou-se que houve concordância substancial em C1 e C2; e apresentou concordância moderada em C8.

O programa Xoran não apresentou concordâncias significativas interobservador. 
Tabela 5.6- Correlação de Spearman entre IP e IQO

\begin{tabular}{|c|c|c|c|c|c|c|c|c|c|c|}
\hline & & & $\mathrm{C} 1$ & $\mathrm{C} 2$ & $\mathrm{C} 3$ & $\mathrm{C} 4$ & $\mathrm{C} 5$ & $\mathrm{C} 6$ & $\mathrm{C} 7$ & $\mathrm{C} 8$ \\
\hline \multirow[t]{9}{*}{ Spearman's } & \multirow[t]{3}{*}{ Xoran } & Correlation &,- 342 &,- 174 &,- 522 &,- 290 &,- 261 & 290 & 174 & 174 \\
\hline & & Sig. (1-tailed) & , 167 & ,315 & 061 & ,208 & ,233 & 208 & ,315 & 315 \\
\hline & & $\mathrm{N}$ & 10 & 10 & 10 & 10 & 10 & 10 & 10 & 10 \\
\hline & \multirow[t]{3}{*}{ Romexis } & $\begin{array}{l}\text { Correlation } \\
\text { Coefficient }\end{array}$ & $-783^{*}$ &,- 495 &,- 363 &,$- 905^{* *}$ &,$- 704^{\star}$ &,$- 663^{*}$ &,$- 661^{*}$ &,- 362 \\
\hline & & Sig. (1-tailed) & ,004 & ,073 & , 151 & , 000 & ,012 & ,018 & 019 & , 152 \\
\hline & & $\mathrm{N}$ & 10 & 10 & 10 & 10 & 10 & 10 & 10 & 10 \\
\hline & \multirow[t]{3}{*}{ Osirix } & $\begin{array}{l}\text { Correlation } \\
\text { Coefficient }\end{array}$ &,$- 688^{*}$ &,- 330 & 071 & - 453 & -509 &,$- 563^{*}$ & -270 &,$- 603^{*}$ \\
\hline & & Sig. (1-tailed) & ,014 & ,176 & ,423 & 095 & ,066 & ,045 & ,226 & ,032 \\
\hline & & $\mathrm{N}$ & 10 & 10 & 10 & 10 & 10 & 10 & 10 & 10 \\
\hline
\end{tabular}

*. Correlação significante $p \leq 0,05$

${ }^{* *}$. Correlação significante $p \leq 0,01$ 
Tabela 5.7- Teste Estatístico Kappa Ponderado intra-observador para a variável IQO

\begin{tabular}{|c|c|c|c|}
\hline & OsiriX & Xoran & Romexis \\
\hline C1 &, 348 &, 091 &, 605 \\
&, $048^{*}$ &, 301 &, $011^{*}$ \\
\hline C2 &, 286 &, 016 &, 474 \\
&, 103 &, 725 &, $032^{*}$ \\
\hline C3 &, 286 &, 118 &, 595 \\
&, 260 &, 389 &, $013^{*}$ \\
\hline C4 &, 800 &, 167 &, 194 \\
&, $010^{*}$ &, 292 &, 429 \\
\hline C5 &, 432 &, 333 &, 167 \\
&, $025^{*}$ &, 114 &, 472 \\
\hline C6 &, 444 &, 118 &, 079 \\
&, 055 &, 389 &, 725 \\
\hline C7 &, 375 &, 014 &, 091 \\
&, $025^{*}$ &, 725 &, 585 \\
\hline C8 &, 412 &, 000 &, 167 \\
&, $026^{*}$ & $-1,000$ &, 336 \\
\hline
\end{tabular}

${ }^{*} \mathrm{p} \leq 0,05$ 
Tabela 5.8: Teste Estatístico Kappa Ponderado inter-observador para a variável IQO

\begin{tabular}{|c|c|c|c|}
\hline & OsiriX & Xoran & Romexis \\
\hline C1 &, 762 &, 118 &, 773 \\
&, $002^{*}$ &, 301 &, $002^{*}$ \\
\hline C2 &, 687 &, 167 &, 687 \\
&, $003^{*}$ &, 292 &, $002^{*}$ \\
\hline C3 &, 400 &, 318 &, 167 \\
&, 197 &, 107 &, 429 \\
\hline C4 &, 400 &, 200 &, 333 \\
&, 197 &, 292 &, 197 \\
\hline C5 &, 500 &, 400 &, 375 \\
&, $038^{\star}$ &, 114 &, 091 \\
\hline C6 &, 483 &, 412 &, 167 \\
&, 065 &, 107 &, 527 \\
\hline C7 &, 143 &, 200 &, 286 \\
&, 292 &, 292 &, 114 \\
\hline C8 &, 405 &, 286 &, 412 \\
&, $035^{*}$ &, 197 &, $022^{*}$ \\
\hline
\end{tabular}

${ }^{*} \mathrm{p} \leq 0,05$ 



\section{DISCUSSÃO}

Diante dos trabalhos estudados é de consenso que a osseointegração no tratamento de implantes depende da qualidade e quantidade óssea disponível nos sítios; a estabilidade óssea primária caracterizada pela ausência de micromovimentos no leito ósseo após o procedimento cirúrgico é o fator chave para o sucesso do tratamento; muitos estudos demonstraram alta falha de tratamentos de implantes em rebordos de qualidade óssea pobre e quantidade óssea insuficiente (Lioubavina-Hack et al., 2006; Parsa et al., 2015; Cortes et al., 2015).

A atrofia ou atresia mandibular é um caso especial devido ao seu baixo conteúdo mineral, para o tratamento de implantes seu risco é alto e requer técnicas cirúrgicas alternativas e maiores informações morfológicas para o planejamento pré-cirúrgico, no presente estudo utilizou-se mandíbulas atróficas por serem casos específicos de baixo conteúdo mineral nas regiões e o risco de falhas é aumentado nesses casos o que torna um desafio para o cirurgião (Cassetta et al., 2014).

Através do auxílio dos recursos de imagem na prática clínica odontológica, a TCFC está amplamente aceita como uma ferramenta precisa para o planejamento de implante dental por ter disponibilidade aos dentistas e custos reduzidos. A TCFC permite realizar avaliação morfológica pré- cirúrgica em três dimensões da cortical óssea e osso trabecular disponível para colocação de implantes dentais, estudos recentes compararam TC à TCFC visto que oferece vantagens como baixa dose de radiação, menores tempos de aquisição de imagem, alta resolução espacial geométrica e baixo custo. Avaliaram a densidade óssea de sítios de implantes pelos valores de pixel da escala de cinza e obtiveram altas correlações; porém no presente estudo não foram comparados a densidade óssea de TC quanto à TCFC, pela limitação desta por não ser projetada para esse fim (Scarfe et al., 2006; Mah et al., 2010; Valiyaparambil et al., 2012; GonzálezGarcia; Monje, 2013; Parsa et al., 2015; Cortes et al., 2015). 
Há controvérsias na literatura sobre o uso de TCFC para estimar a densidade mineral óssea a partir de U.H, uma vez que são ferramentas projetadas originalmente para TCMS e muitas vezes os valores são superestimados, e não podem serem utilizados para TCFC; alguns estudos portanto essa escala não é considerada nesse estudo (Isoda et al., 2012; Silva et al., 2012; Valiyaparambil et al., 2012; Nomura et al., 2010; Parsa et al., 2013, 2015; González- Garcia; Monje, 2013; Ibrahim et al., 2014; Razi et al., 2014; Salimov et al., 2014; Cortes et al., 2015).

Diante das inúmeras vantagens sobre a TCFC, a utilização dessa modalidade imaginológica nas especialidades odontológicas está em rápido crescimento e, portanto, mais acessível para os especialistas, por conseguinte a validade da TCFC para avaliação da qualidade óssea tem sido amplamente estudada. Estudos recentes demonstraram fortes correlações entre as medidas de U.H derivados da TC e IP derivados da TCFC para estimar a densidade mineral óssea e prever a qualidade óssea em potenciais sítios de implante, porém conversões para valores absolutos são necessários para melhor acurácia clínica (Naitoh et al., 2010; Nomura et al., 2010; Parsa et al., 2013; Valiyaparambil et al., 2012; Cassetta et al., 2014).

Devido à uma falta de norma técnica para o desenvolvimento dos sistemas de TCFC há uma grande disparidade nos parâmetros inerentes à técnica de cada modelo de equipamento tomográfico, modos de aquisição de imagem, resolução de imagem, o tamanho do FOV, radiação dispersa, artefatos e limitações de reconstruções algorítmicas que podem alterar os valores de IP nas imagens. Muitos autores acreditam no desenvolvimento de um programa para TCFC que permite a correção uniforme desses parâmetros para que no futuro as imagens de TCFC nos forneça parâmetros para uma avaliação confiável da qualidade óssea para um planejamento de implante; embora muitos estudos mostrem alta correlação de valores de IP em TCFC assim como o presente estudo (Naitoh et al., 2010; Nomura et al., 2010; Nackaerts et al., 2015; Mah et al., 2010; Silva et al., 2012; Parsa et al., 2013; Pawels et al., 2015). 
A TCFC tem como limitação ruídos de imagem, espalhamento e artefatos produzidos pelos equipamentos e podem variar de acordo com o modelo, esses fatores podem superestimar os valores de IP e por fim afetar a precisão para avaliação da densidade óssea em um local, além disso os valores que representam a densidade óssea de um equipamento de TCFC não é reprodutível em equipamento diferente, acredita-se que há diferenças entre equipamentos estudados (Nackaerts et al., 2015; Isoda et al., 2012; Silva et al., 2012; Parsa et al., 2013).

Recentes estudos avaliaram a acurácia de TCFC na avaliação da densidade óssea trabecular utilizando a TCMS e micro-CT como padrão ouro e concluíram que há forte correlação entre os valores de IP de TCFC e a fração volume ósseo (BV/TV) sugerindo alto potencial na avaliação da qualidade óssea no sítio do implante; embora a técnica não utilizada em nosso estudo verificou-se que a TCFC mostrou-se efetiva na avaliação de estrutura trabecular óssea; o presente estudo mostrou que a TCFC pode avaliar o osso trabecular e apresentou fortes correlações para entre o IQO das imagens; em decorrência às novas gerações de equipamentos tomográficos as imagens estão apresentando melhores resoluções e portanto melhores detalhes para a avaliação da estrutura óssea trabecular (González- Garcia; Monje, 2013; Parsa et al., 2013; Ibrahim et al., 2014, Cortes et al., 2015).

Alguns estudos mostraram a correlação entre densidade óssea estimada pela TCFC e estabilidade de implantes, esta considerada um dos fatores importantes para o êxito do implante, além disso, muitos autores consideram a qualidade óssea como fator chave que influencia a osseointegração e o sucesso do tratamento, por isso há a necessidade de uma ferramenta precisa para o planejamento pré-cirúrgico adequado; (Isoda et al., 2012; Valiyaparambil et al., 2012; Salimov et al., 2014).

Alguns autores avaliaram a eficácia da TCFC para estimar a densidade mineral óssea a partir da correlação de valores de IP, parâmetros de estabilidade óssea e índice de qualidade óssea de Lekholm e Zarb (1985), concluíram que é possível estimar a densidade mineral óssea no planejamento pré-cirúrgico (Nomura et al., 2010; Salimov et al., 2014)

A limitação do nosso estudo é verificada por tratar-se de um estudo in-vitro, foi utilizado mandíbulas atróficas secas sem presença de tecido mole e dentes, portanto materiais que poderiam causar artefatos não foram incluídos, diferentemente de casos clínicos. 
Foi utilizada a ferramenta $\mathrm{ROI}$ de pequena dimensão, que pelo seu tamanho há grandes diferenças entre valores de IP.

Os valores de IP obtidos de mandíbulas secas podem desviar-se da situação clínica.

Entretanto, estudos com outros equipamentos e outras áreas do complexo maxilomandibular visando obter informações destinadas ao planejamento de implante dental, escolhas da técnica cirúrgica e em casos clínicos são sugeridos.

A necessidade de uma classificação de qualidade óssea objetiva e quantitativa de densidade óssea que pode ser aplicado no planejamento pré-operatório, e que não dependa da experiência do operador é necessária.

O desenvolvimento de um programa para diagnóstico e planejamento utilizando ferramentas reprodutíveis e de boa acurácia pré-operatória visando a qualidade óssea. 


\section{CONCLUSÕES}

Diante dos resultados obtidos pode-se inferir que os programas Romexis e OsiriX apresentaram melhor acuidade para a avaliação subjetiva de qualidade óssea, em contrapartida o programa Xoran apresentou inconsistência de dados.

Houve correlação entre Intensidade de Pixel e Índice de Qualidade óssea nos programas OsiriX e Romexis

É possível ter o auxílio de programa de manipulação de tomografias para avaliação pré-cirúrgica e obter informações de qualidade óssea, como um dos fatores que possam interferir na estabilidade do implante e o sucesso do tratamento. 



\section{REFERÊNCIAS ${ }^{1}$}

Al-Ekrish A A, Ekram M A. Comparative study of the aacuracy and reliability of multidetector computed tomography and cone beam computed tomography in the assessment of dental implant site dimension. Dentomaxillofac Radiol. 2011; 40: 6775.

Alsaadi G, Quirynen M, Michiles K, Teughels W, Komárek A, van Steenberghe D. Impact of local and systemic factors on the incidence of failures up to abutment connection with modified surface oral implants. J Clin Periodontol. 2008;35:51-7.

Akca K, Iplikcioglu $\mathrm{H}$. Evaluation of the effect of the residual bone angulation on implant-supported fixed prostheses in mandibular posterior edentulism. Part I: Spiral computed tomography study. Implant Dent. 2001;10:216-22.

Arai Y, Tammisalo E; Iwai K. Development of a compact computed tomographic apparatus for dental use. Dentomaxillofac Radiol. 1999; 28: 245-8.

Ballrick JW, Palomo JM, Ruch E, Amberman BD, Hans MG. Image distortion and spatial resolution of a commercially available cone-beam computed tomography machine. Am J Orthod Dentofacial Orthop. 2008 Oct;134(4):573-82. doi: 10.1016/j.ajodo.2007.11.025.

Bergkvist G, Koh KJ, Sahlholm S, Klintström E, Lindh C. Bone density at implant sites and its relationship to assessment of bone quality and treatment outcome. Int $\mathrm{J}$ Oral Maxillofac Implants. 2010 Mar-Apr;25(2):321-8.

\footnotetext{
${ }^{1}$ De acordo com Estilo Vancouver.
} 
Benavides E, Rios HF, Ganz SD, An CH, Resnik R, Reardon GT, Feldman SJ, Mah JK, Hatcher D, Kim MJ, Sohn DS, Palti A, Perel ML, Judy KW, Misch CE, Wang HL. Use of cone beam computed tomography in implant dentistry: the International Congress of Oral Implantologists consensus report. Implant Dent. 2012 Apr;21(2):7886. doi: 10.1097/ID.0b013e31824885b5

Bryant SR. The effects of age, jaw site, and bone condition on oral implant outcomes. Int J Prosthodont. 1998 Sep-Oct;11(5):470-90.

Cassetta M, Stefanelli LV, Pacifici A, Pacifici L, Barbato E. How accurate is CBCT in measuring bone density? A comparative CBCT-CT in vitro study. Clin Implant Dent Relat Res. 2014 Aug;16(4):471-8.

Cortes AR, Eimar H, Barbosa JS, Costa C, Arita ES, Tamimi F. Sensitivity and specificity of radiographic methods for predicting insertion torque of dental implants. $J$ Periodontol. 2015. May;86(5):646-55.

Costa C, Felicori SM, Cyrne MAM, Caputo BV, Paiva TBD. Estudo tomodensitométrico de áreas desdentadas da mandíbula por meio da tomografia computadorizada de feixe-cônico. J. Health Sci. Inst,. 2010; 28(4): 311-14.

Chan HL, Misch K, Wang HL. Dental imaging in implant treatment planning. Implant Dent. 2010; 19: 288-98.

Drage NA, Palmer RM, Blake G, Wilson R, Crane F, Fogelman I. A comparison of bone mineral density in the spine, hip and jaws of edentulous subjects. Clin Oral Implants Res. 2007 Aug;18(4):496-00.

Diederichs, G, Link TM, Kentenich M, Schwie- ger K, Huber MB, Burghardt AJ, Majumdar S, Rogalla P, Issever AS. Assessment of trabecular bone structure of the calcaneus using multi-detector CT: correlation with microCT and biomechanical testing. Bone. 2009 May;44(5):976-83. doi: 10.1016/j.bone.2009.01.372

Frederiksen, NL. Diagnostic imaging in dental implantology. Oral Surg Oral Med, Oral Pathol, Oral Radiol Endod. 1995; 80:540 - 54

Friberg B, Sennerby L, Roos J, Lekholm U. Identification of bone quality in conjunction with insertion of titanium implants. A pilot study in jaw autopsy specimens. Clinical Oral Implants Research. 1995;6:213-9. 
Fuh L J, Huang HL, Chen CS, Fu KL, Shen YW, Tu MG, Shen WC, Hsu JT. Variations in bone density at dental implant sites in different regions of the jawbone. J Oral Rehabil.2010;37: 346-51.

Goiato MC, dos Santos DM, Santiago JF Jr, Moreno A, Pellizzer EP. Longevity of dental implants in type IV bone: a systematic review. Int J Oral Maxillofac Surg. 2014 Sep;43(9):1108-16. doi: 10.1016/j.ijom.2014.02.016.

González- García R, Monje F. The reliability of cone-beam computed tomography to assess bone density at dental implant recipient sites: a histomorphometric analysis by micro-CT. Clin Oral Impl. 2013; 24: 871-9.

Ibrahim N, Parsa A, Hassan B, van der Stelt P, Aartman IHA, Nambiar P. Influence of object location in different FOVs on trabecular bone microstructure measurements of human mandible: a cone beam CT study. Dentomaxillofac Radiol.

2014;43(2):20130329. doi: 10.1259/dmfr.20130329.

Isoda K, Ayukawa Y, Tsukiyama Y, Sogo M, Matsushita Y, Koyano K. Relationship between the bone density estimated by cone-beam computed tomography and the primary stability of dental implants. Clin Oral Implants Res 2012; 23:832- 6.

Kobayashi K, Shimoda S, Nakagawa Y, Yamamoto A. Accuracy in measurement of distance using limited cone-beam computerized tomography. Int J Oral Maxillofac Implants. 2004 Mar-Apr; 19(2): 228-31

Lekholm U, Zarb GA. Patient selection and preparation. In: Branemark, P.I., Zarb GA,Al brektsson T., (eds): Tissue integrated prosthesis: Osseointegration in clinical dentistry. Chicago Quintessence Publishing Co; 1985.p.199-28.

Liang X, Jacobs R, Hassan B, Li L, Pauwels R, Corpas L, Souza PC, Martens W, Shahbazian M, Alonso A, Lambrichts I. A comparative evaluation of cone beam computed tomography (cbct) and multi-slice Ct (Msct) Part I. on subjective image quality. Eur J Radiol. 2010; 75:265-9.

Lindh C, Obrant K, Petersson A. Maxillary bone mineral density and its relationship to the bone mineral density of the lumbar spine and hip. Oral Surg Oral Med Oral Pathol Oral Radiol Endod. 2004: 98:102-9.

Lioubavina- Hack N, Lang NP, Karring T. Significance of primary stability for osseointegration of dental implants. Clin Oral Implants Res. 2006; 17: 244-50. 
Loubele M, Van Assche N, Carpentier K, Maes F, Jacobs R, van Steenberghe D, et al. Comparative localized linear accuracy of small-field cone beam CT and multislice CT for alveolar bone measurements. Oral Surg Oral Med Oral Pathol Oral Radiol Endod. 2008;105:512-8.

Mah P, Reeves TE, McDavid WD. Deriving Hounsfield units using grey levels in cone-beam computed tomography. Dentomaxillofac Radiol. 2010; 39: 323-35.

Misch CE. Bone classification, training keys to implant success. Dent Today. 1989; 8: 39-44.

Misch CE. Implantes Dentais Contemporâneos.3a ed. Rio de Janeiro: Elsevier; 2008.

Molteni R. Prospects and challenges of rendering tissue density in Hounsfield units for cone beam computed tomography. Oral Surg Oral Med Oral Pathol Oral Radiol. 2013 Jul; 116(1):105-19.

Mukaka M. A guide to appropriate use of Correlation coefficient in medical research. Malawi Medical Journal: The Journal of Medical Association of Malawi. 2012; 24(3): 69-71.

Nackaerts O, Depypere M, Zhang G, Vandenberghe B, Maes F, Jacobs R; SEDENTEXCT Consortium. Segmentation of Trabecular Jaw Bone on Cone Beam CT Datasets. Clin Implant Dent Relat Res. 2015 Dec; 17(6):1082-91.

Naitoh M, Hirukawa A, Katsumata A, Ariji E. Prospective study to estimate mandibular cancellous bone density using large-volume cone-beam computed tomography. Clin Oral Implants Res. 2010; 21: 1309-13.

Nomura $\mathrm{Y}$, Watanabe $\mathrm{H}$, Honda E, Kurabayashi T. Reliability of voxel values from cone-beam computed tomography for Dental use in evaluating bone mineral density. Clin Oral Implants Res. 2010; 21: 558-62.

Norton MR, Gamble C. Bone classification: An objective scale of bone density using the computerized tomography scan. Clin Oral Implants Res. 2001;12: 79-84.

Parsa A, Ibrahim N, Hassan B, Motroni A, van der Stelt P, Wismeijer D. Influence of cone beam CT scanning parameters on grey value measurements at an implant site. 
Dentomaxillofac Radiol. 2013;42(3):79884780. doi: 10.1259/dmfr/79884780. Epub 2012 Aug 29.

Parsa A, Ibrahim N, Hassan B, van der Stelt P, Wismeijer D. Bone quality evaluation at dental implant site using multislice CT, micro-CT and cone beam CT Clin Oral Impl. 2015;26(1):e1-7. doi: 10.1111/clr.12315. Epub 2013 Dec 11.

Pauwels R, Araki K, Siewerdsen JH, Thongvigitmanee SS. Technical aspects of dental CBCT: state of the art. Dentomaxillofac Radiol. 2015; 44(1):20140224. doi: $10.1259 / \mathrm{dmfr} .20140224$.

Peñarrocha M, Palomar M, Sanchis JM, Guarinos J, Balaguer J. Radiologic study of marginal bone loss around 108 dental implants and its relationship to smoking, implant location, and morphology. Int J Oral Maxillofac Implants. 2004 Nov-Dec; 19(6):861-7.

Razi T, Niknami M, Ghazani FA. Relationship between Hounsfield unit in CT scan and gray scale in CBCT. J Dent Res Dent Clin Dent Prospects. 2014: 8(2): 107.

Resnik RR, Kircos L, Misch CE. Diagnostic Imaging and Techniques, In:

Contemporary Implant Dentistry, C.E. Misch, Mosby: Elsevier; 2008.p.38-67.

Ribeiro-Rotta RF, Lindh C, Pereira AC, Rohlin M. Ambiguity in bone tissue characteristics as presents in studies on dental implant planning and placement: a systematic review. Clin Oral Impl Res. 2011; 22: 789-01.

Salimov F, Tatli U, Kurkcu M, Akoglan M, Oztunc H, Kurtoglu C. Evaluation of relationship between pre-operative bone density values derived from cone beam computed tomography and implant stability parameters: A clinical study. Clin Oral Implants Res. 2014; 25: 1016-21.

Scarfe WC, Farman AG, Sukovic P. Clinical applications of cone-beam computed tomography in dental practice. J Can Dent Assoc. 2006; 72:75-80.

Shapurian T, Damoulis PD, Reiser GM, Griffin TJ, Rand WM. Quantitative evaluation of bone density using the Hounsfield index. Int J Oral Maxillofac Implants. 2006 MarApr; 21(2): 290-7.

, Almeida SM. Bone density: comparative evaluation of Hounsfield units in multislice and cone-beam computed tomography. Braz Oral Res. 2012 Nov-Dec; 26(6): 550-6. 
Suomalainen A, Vehmas T, Kortesniemi M, Robinson S, Peltola J. Accuracy of linear measurements using dental cone beam and conventional multislice computed tomography. Dentomaxillofacial Radiol. 2008; 37:10-7.

Sukovic P. Cone beam computed tomography in craniofacial imaging. Orthod Craniofac Res. 2003; 6(suppl 1):31-6, discussion 179-82.

Stellingsma C, Vissink A, Meijer HJ, Kuiper C, Raghoebar GM. Implantology and the severely resorbed edentulous mandible. Crit Rev Oral Biol Med. 2004 Jul 1; 15(4): 240-8.

Tozoğlu U, Cakur B. Evaluation of the morphological changes in the mandible for dentate and totally edentate elderly population using cone-beam computed tomography. Surg Radiol Anat. 2014 Sep;36(7):643-9

Trisi P, Rao W. Bone classification: clinical-histomorphometric comparison. Clin Oral Implants Res.1999;10: 1-7.

Turkyilmaz I, Tözüm TF, Tümer C. Bone density assessments of oral implant sites using computerized tomography. J Oral Rehabil. 2007:34: 267-72.

Turkyilmaz I, Ozan O, Yilmaz B, Ersoy AE. Determination of Bone Quality of 372 Implant Recipient Sites Using Hounsfield Unit from Computerized Tomography a clinical study. Clin Implant Dent Relat Res. 2008 Dec;10(4):238-44.

Valiyaparambil JV, Yamany I, Ortiz D, Shafer DM, Pendrys D, Freilich M, et al. Bone quality evaluation: comparison of cone beam computed tomography and subjective surgical assessment. Int J Oral Maxillofac Implants. 2012 Sep-Oct;27(5):1271-7.

Viera AJ, Garrett JM. Understanding interobserver agreement: the kappa statistic. Fam Med. 2005 May;37(5):360-3.

White SC. Cone-beam imaging in dentistry. Health physics. 2008; 95(5):628-37. 


\section{FACULDADE DE ODONTOLOGIA DA UNIVERSIDADE DE SÃO}

Plataforms :rasil

\section{PARECER CONSUBSTANCIADO DO CEP}

\section{DADOS DO PROJETO DE PESQUISA}

Título da Pesquisa: Intensidade de pixel e sua correlação com o Índice de Qualidade Óssea de mandíbulas atróficas

Pesquisador: Claudio Costa

Área Temática:

Versão: 1

CAAE: 44495415.8 .0000 .0075

Instituição Proponente: Universidade de Sao Paulo

Patrocinador Principal: Financiamento Próprio

\section{DADOS DO PARECER}

Número do Parecer: 1.070 .765

Data da Relatoria: 20/05/2015

Apresentação do Projeto:

A partir de imagens tomográficas de dez mandíbulas atróficas pertencentes ao banco de dados digitais do LAPI - Laboratório para Análise e Processamento de Imagens da Faculdade de Odontologia da Universidade de São Paulo serão realizadas análises da qualidade óssea com o uso de três softwares de pós processamento. Não haverá portanto exposição de nenhum indivíduo à radiação, sendo o exame estritamente observacional.

\section{Objetivo da Pesquisa:}

Verificar diferenças entre os softwares Xoran, Romexis e OsiriX na análise dos dados de intensidade de pixel (tons de cinza) e Índice de Qualidade

Óssea. Correlacionar ambos os métodos de estudo da qualidade do tecido ósseo nas regiões anterior e posterior das mandíbulas.

\section{Avaliação dos Riscos e Benefícios:}

Não existem riscos a saúde humana. Pesquisa baseada em banco de dados digitais pertencentes ao LAPIFOUSP, estando preservados os dados dos indivíduos da amostra.

Comentários e Considerações sobre a Pesquisa:

Determinar a existência de diferenças de leituras das intensidades de pixels entre os softwares.

\begin{tabular}{|c|c|c|}
\hline $\begin{array}{l}\text { Endereço: Av Prof Lineu Preste } \\
\text { Bairro: Cidade Universitária } \\
\text { UF: SP }\end{array}$ & $\begin{array}{l}\text { S } 2227 \\
\text { SAO PAULO CEP: }\end{array}$ & 05.508-900 \\
\hline Telefone: (11)3091-7960 & Fax: $(11) 3091-7814$ & E-mail: cepfo@usp.br \\
\hline
\end{tabular}




\section{FACULDADE DE ODONTOLOGIA DA UNIVERSIDADE DE SÃO}

Continuação do Parecer: 1.070 .765

Determinar a existência de diferenças de Índice de Qualidade Óssea (IQO) entre os softwares. Determinar a relação entre a intensidade de pixel e IQO no planejamento virtual.

Avaliar se o tipo de extensão é capaz de modificar os dados das leituras de intensidade de pixel. Verificar se existem diferenças intra e

interobservadores para os softwares de pós processamento.

Considerações sobre os Termos de apresentação obrigatória:

Apresentou folha de rosto, projeto e infirmações básicas.

Recomendações:

Tendo em vista a legislação vigente, devem ser encaminhados ao CEP-FOUSP relatórios parciais semestrais referentes ao andamento da pesquisa e relatório final ao término do trabalho. Qualquer modificação do projeto original deve ser apresentada a este CEP, de forma objetiva e com justificativas, para nova apreciação.

Conclusões ou Pendências e Lista de Inadequações:

Aprovado

Situação do Parecer:

Aprovado

Necessita Apreciação da CONEP:

Não

Considerações Finais a critério do CEP:

SAO PAULO, 20 de Maio de 2015

Assinado por:

Maria Gabriela Haye Biazevic

(Coordenador)

\begin{tabular}{|c|c|c|c|}
\hline Bairro: & Cidade Universitária & CEP: & $05.508-900$ \\
\hline UF: SP & Município: & SAO PAULO & \\
\hline Telefone & : (11)3091-7960 & Fax: (11)3091-7814 & E-mail: \\
\hline
\end{tabular}

